\title{
River flows affect the growth of a tropical finfish in the wet- dry rivers of northern Australia, with implications for water resource development
}

\author{
Susannah M. Leahy (D) Julie B. Robins
}

Received: 16 February 2021 / Revised: 9 June 2021 / Accepted: 12 June 2021

(C) Crown 2021

\begin{abstract}
Freshwater is a critical input to estuaries but is under increasing demand to support upstream human activities. In this study, otolith biochronology was used to quantify the relationship between river discharge and juvenile growth rates of barramundi (Lates calcarifer) in three regions of the Gulf of Carpentaria in northern Australia. In all regions, river discharge had a strong positive effect on juvenile growth rates. Models were also developed which incorporated the Southern Oscillation Index (SOI) and the Madden-Julian Oscillation (MJO). SOI values corresponding to La Niña events had strong positive consequences for juvenile barramundi growth rates in all regions, and the intensity of positive wet season MJO pulses had a strong positive effect on growth rates in the perennially flowing river, but not the
\end{abstract}

Handling editor: Antti P Eloranta

Supplementary Information The online version contains supplementary material available at https://doi.org/10.1007/ s10750-021-04641-7.

\section{S. M. Leahy ( $\square)$}

Queensland Department of Agriculture and Fisheries, Agri-Science Queensland, Northern Fisheries Centre, Cairns, QLD, Australia

e-mail: Susannah.Leahy@daf.qld.gov.au

\section{J. B. Robins}

Queensland Department of Agriculture and Fisheries, Agri-Science Queensland, EcoSciences Precinct,

Brisbane, QLD, Australia intermittently flowing rivers. The consequences of three hypothetical water development scenarios were estimated for the perennial river. The model predicted a $12 \%, 8 \%$ and $1 \%$ reduction in annual barramundi growth rates under proposed scenarios for $18 \%, 8 \%$, and $3 \%$ reduction in river discharge, respectively. Fish growth is a robust, quantitative metric that can be monitored pre and post water resource development to identify the least impactful development scenario and monitor its compliance and success through time.

Keywords Barramundi - Otolith increment analysis - Water harvesting $\cdot$ SOI $\cdot$ MJO $\cdot$ Gulf of Carpentaria

\section{Introduction}

Freshwater is a crucial resource for life and is often a limiting factor for ecological processes and human needs. In estuarine systems, freshwater inputs increase aquatic primary productivity by increasing submerged habitat availability through inundation, and in some cases by stimulating growth of primary producers via nutrient inputs (Davies et al., 2008; Pettit et al., 2017). This supports increases in spawning, recruitment, and growth of species at higher trophic levels (Pettit et al., 2017). 
Humans benefit from freshwater flows through the many ecosystem services provided by wetland areas (Mitsch et al., 2015). However, these ecosystem freshwater needs can be in direct opposition to freshwater extraction demands for human use (Grey \& Sadoff, 2007; Stewart-Koster \& Bunn, 2016). Balancing the competing demands on finite water resources is key to sustainable freshwater use (Stewart-Koster \& Bunn, 2016). There are numerous global examples where the overallocation of freshwater resources for upstream human purposes have severely stressed downstream ecosystems and have proven difficult to undo or restore, notably the Colorado River (Kendy et al., 2017), and the Murray-Darling River (Kingsford et al., 2011).

The Gulf of Carpentaria and associated river catchments in northern Australia are an example of where finite water resources support a variety of ecosystem services but where there is also increasing demand for upstream development of freshwater resources for irrigated agriculture (Petheram et al., 2018b), and potentially mining. Like many jurisdictions worldwide, government legislation requires the sustainable use and management of freshwater resources, with management decisions needing to actively balance upstream use against the needs of downstream ecosystems and assets (Acreman et al., 2014; McGregor et al., 2018). The Gulf of Carpentaria has a coastline over $2,000 \mathrm{~km}$ long, and receives freshwater input from over 25 major catchments with a total area of approximately $647,000 \mathrm{~km}^{2}$ (Bureau of Meteorology, 2012a). Rainfall and associated river flow is the main source of freshwater input and occurs in a distinct wet-dry cycle (Warner, 1986; Warfe et al., 2011) aligned with the monsoonal wet season in the austral summer. Rainfall patterns are variable between catchments and years but occur almost exclusively between November and April, with average annual totals of 650 to $1,200 \mathrm{~mm}$ (Bureau of Meteorology, 2012a). The resulting river flows and flooding are crucial for inundating floodplains, connecting waterways that are disconnected in the dry season, and stimulating primary productivity (Whitehouse, 1943; Davies et al., 2008; Warfe et al., 2011; Pettit et al., 2017; Burford et al., 2020). Seasonal flooding is an important driver of high-value inshore finfish and offshore penaeid shrimp fisheries in the Gulf of Carpentaria (Vance et al., 1985; Halliday et al., 2012). However, harvesting and storage of wet season river flows are prerequisites for proposed major developments in northern Australia (Petheram et al., 2008, 2018b). There are potential implications of upstream development on downstream ecological processes and fisheries that rely on the same river flows (Gillanders \& Kingsford, 2002; Stewart-Koster \& Bunn, 2016; Broadley et al., 2020).

Barramundi [Lates calcarifer (Bloch, 1790)] is a key commercial fishery species in the Gulf of Carpentaria, and is also important recreationally, socially and culturally to regional communities (Campbell et al., 2017) and more broadly throughout northern Australia (Streipert et al., 2019). Barramundi is a facultative catadromous species (i.e. non-obligate) with a spatially and temporally variable proportion of individuals accessing freshwater habitats during their life (Pender \& Griffin, 1996; de Lestang et al., 2001; Milton \& Chenery, 2005; Milton et al., 2008; Halliday et al., 2012; Crook et al., 2016). River flows have long been considered highly beneficial to barramundi populations (Dunstan, 1959). Seasonal freshwater flows provide connectivity between upstream and downstream habitats, and cause changes in food availability with impacts on growth, survival, recruitment, and year-class strength (Robins et al. 2005). In particular, river flows can increase growth rates of barramundi (Robins et al., 2006), with access to the freshwater habitats increasing juvenile growth rates by 25\% compared with estuarine habitats (Roberts et al., 2019). Water resource development has the potential to modify and impact negatively on these mechanisms.

Regional or continental-scale atmospheric indices have also been correlated to fish growth rates (Martino et al., 2019) and catch rates (Balston, 2008). Atmospheric indices can serve as a proxy for a conglomerate of local environmental conditions over various periods of time, which in some cases can serve as better predictors of ecological processes than direct measures of local conditions (Hallett et al., 2004). A number of atmospheric indices influence conditions in northern Australia (Lisonbee \& Ribbe, 2021), and are critical to informing rainfall predictions (Hudson et al., 2017) and making recommendations around agricultural planning decisions (Cobon et al., 2020; Cowan et al., 2020). Atmospheric indices can therefore provide both a proxy for river flow data that is incomplete, and potentially a tool for predicting seasonal river discharge. 
Growth rates in fish can be measured directly through mark-recapture studies (e.g. Robins et al., 2006) or inferred through measurements of otolith increment widths (e.g. Roberts et al., 2019). Otolith increment widths are correlated with somatic growth (Pannella, 1971; Casselman, 1990; Campana \& Thorrold, 2001) and have been extensively used across a wide range of species to identify favourable conditions for growth at daily and annual timescales (LeBreton \& Beamish, 2000; Sponaugle, 2009; Morrongiello et al., 2012; ICES, 2014; Tonkin et al., 2017). Although otolith increment widths may not be as accurate as direct measurement of changes to fish length over time (Booth, 2014), using otolith increment widths as a proxy for growth is cost effective, and can take advantage of historical otolith collections to reconstruct growth rates over years and regions for which adequate samples are available.

The goals of the current study were (1) to quantify the relationship between river discharge volume and timing and juvenile growth of barramundi across three wet-dry tropical catchments with differing flow regimes, and (2) to subsequently use the identified relationships to assess the relative impact of hypothetical water development scenarios on growth rates of juvenile barramundi. Three catchments in the Gulf of Carpentaria, northern Australia, that are the subject of water resource planning for potential freshwater harvesting (Burford et al., 2020), were selected as study regions. Barramundi growth was derived from otolith increment widths from a large-scale historic fishery monitoring collection sampled between 2000 and 2018 by the Queensland Department of Agriculture and Fisheries (DAF). We also assessed the timing of marginal increment formation to confirm annuli deposition for Gulf of Carpentaria barramundi. Measurement of increment widths to assess growth variability were focused on the first three annuli. We expected interannual differences in growth rates resulting from river flows would be most apparent during this ontogenetic stage, whether through habitat availability (Russell, 2014; Roberts et al., 2019) or increased food availability (Davies et al., 2008; Pettit et al., 2017).

\section{Methods}

Study area

The current study focuses on three regions along a $600 \mathrm{~km}$ north-south latitudinal gradient of the Gulf of Carpentaria, where three large rivers (the Mitchell, Gilbert and Flinders) discharge into marine waters (Fig. 1). The Mitchell, Gilbert, and Flinders rivers have mean annual end of system discharge of 13,000 GL/year $\left(1\right.$ gigalitre $\left.=10^{9} \mathrm{~L}\right), 5,304 \mathrm{GL} /$ year, and 1,982 GL/year respectively (Broadley et al., 2020). The three regions experience the wet-dry cycle typical of northern Australia (Warfe et al., 2011), with generally summer-associated flow events. In some years, large river flows (i.e. discharge volume) result in extensive inundation of floodplains across tens of thousands of square kilometres associated with the lower river deltas (Warfe et al., 2011), supporting high primary productivity and widespread habitat connectivity (Whitehouse, 1943; Warfe et al., 2011; Burford et al., 2020). The Mitchell River has year-round flow (Class 3: perennial river, summer runoff dominant, Kennard et al., 2010) due to rainfall in the upper catchment, which borders the very high rainfall ( $>1200 \mathrm{~mm} /$ year) Wet Tropics region around Cairns (Fig. 1). The Flinders and Gilbert rivers have more intermittent river flows, typically with 100 to 200 zero-flow days per year (Class 10: highly intermittent river, summer runoff dominant, Kennard et al., 2010).

\section{Study species}

The barramundi is a protandrous and facultative catadromous species (Dunstan, 1959; Moore, 1979; McCulloch et al., 2005; Russell, 2014). It displays characteristics consistent with a periodic life history strategy, i.e. slow growing, long lived, delayed maturation, and variable recruitment (Winemiller \& Rose, 1992; King \& McFarlane, 2003). Barramundi spawning grounds are typically in the mouths of rivers and features of the coastal foreshore (e.g. sand banks, gutters, embayments). Spawning events are closely related to lunar and tidal cycles in spring and summer (Moore, 1982; Garrett, 1987), which precedes and overlaps with the austral summer wet season (November to March). Experimentally, optimal hatching success of fertilized barramundi eggs occurs at salinities of 20 to $30 \mathrm{ppt}$ (Maneewong, 1987), and in 


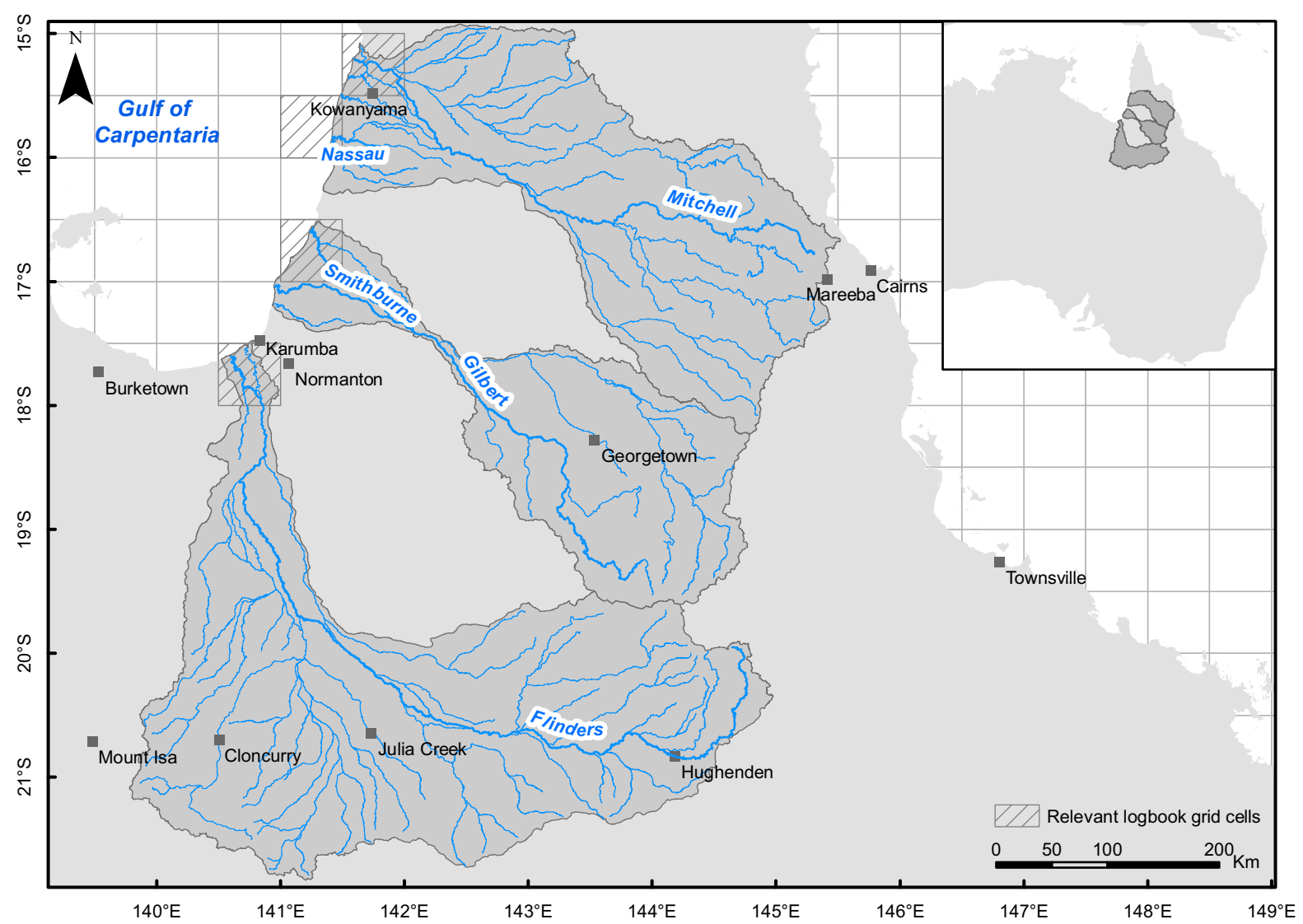

Fig. 1 Regional map with the location of the study regions and their major watercourses, and Queensland commercial fishery logbook grids from which otoliths were selected for each region

wild environments barramundi can spawn well upstream in estuaries when salinities are high (i.e. 28 to $36 \mathrm{ppt}$, Maneewong, 1987). During their first few years of life, juvenile barramundi can be found in a variety of habitats. Initially juvenile barramundi use seasonally high tides to access supralittoral nursey habitats including swamps (Russell \& Garrett, 1983), with subsequent upstream movement to brackish or freshwater habitats enhanced and facilitated by wet season flooding (Davis, 1985). Individuals typically return to saltwater between 2 to 5 years of age, which coincides with male sexual maturity, and then transition to mature females at five to seven years of age (Moore, 1979; Grey, 1987; Russell, 2014).

Otolith data

Commercial catches of barramundi from the Southern Gulf of Carpentaria genetic stock have been monitored (details in Supplemental Material 1). Major townships are included for context. Inset: location of the study regions in the context of the Australian continent

annually for length, age and sex since 2000 (Fisheries Queensland, 2010). This includes collection and thinsectioning ( 350 to $400 \mu \mathrm{m}$ ) of sagittal otoliths for agedetermination as per standard protocols (Fisheries Queensland, 2010; 2012) that have been reported on elsewhere (Wright et al., 2021). Thin-sectioned barramundi otoliths were retrieved from this historic collection for collection years between 2000 and 2018 (Supplementary Material 1). Samples were supplemented with thin-sectioned barramundi otoliths collected between March 2008 and January 2011 from the Flinders and Mitchell rivers by a Queensland Department of Agriculture and Fisheries research project (Halliday et al., 2012).

Age estimates and increment width measurements were taken from still images of transverse otolith sections viewed using reflected LED light at $16 \times$ magnification on a Leica MZ6 microscope and captured on a Leica DFC295 camera (Leica- 
Microsystems, Germany). When viewed using reflected light, annual increments in barramundi otoliths appear as pairs of wide translucent (fast growth) and narrow opaque (slow growth) zones (Stuart \& McKillup, 2002). In northern Australia, barramundi growth rates are highest during the hot wet season (peaking in February/March, Xiao, 1999), during which time the wide translucent zone is formed on the otolith. Growth rates slow during the cool dry season from approximately May to October (Xiao, 1999, 2000), during which time the narrow opaque zone is formed (Staunton-Smith et al., 2004). Barramundi spawn in the southern Gulf of Carpentaria between November and March each year, with a peak in December/January (Davis, 1985). We assigned individuals to year classes based on standard protocols for Queensland barramundi, whereby the nominal birth date is 1 January (Fisheries Queensland, 2012). A year class includes all individuals from the same spawning season (i.e. November to March).

Age was estimated from two readings carried out in separate sessions by a single reader. The Index of Average Percent Error (IAPE) was $<3 \%$, which is considered to indicate sufficiently precise age estimates (Chilton \& Beamish, 1982; Robertson \& Morison, 1999), and is a quality assurance standard for barramundi ageing in Queensland (McDougall, 2004; Fisheries Queensland, 2012). If the age estimates differed between reading sessions, the otolith section was read for a third time by the same reader and the consensus age was used. The relative frequency of otolith edge types in samples collected between January and October was assessed to confirm the timing of formation of the slow growth opaque band.

For all samples, increment widths were measured from a polyline laid along the reading plane for otolith ageing, which is the clearest path near the ventral edge of the sulcus acusticus, perpendicular to the axis of increment formation (Supplementary Material 2, similar to Matta et al., 2010; Morrongiello et al., 2014; Rountrey et al., 2014; Katayama, 2018; Martino et al., 2019). We define the first increment width as the measured distance between the otolith core to the area of heightened luminosity (i.e. most opaque area) in the first opaque zone (i.e. increment 1) to capture the fast summer and slow winter growth experienced by the fish in its first year of life. The distance between the area of heightened luminosity in the first opaque zone to the area of heightened luminosity in the second opaque zone (i.e. increment 2) represented growth in a fish's second year of life, and so on for growth in its third year. Image-Pro Plus 7.0 (Media Cybernetics, USA) was used to identify changes in luminosity associated with opaque zones and thus assist in the placement of a point marker from which to measure increment widths (Supplementary Material 2).

Measurements of small morphometric characteristics are disproportionately vulnerable to measurement-effect errors (Yezerinac et al., 1992). This is especially the case in otolith increment width studies, where measurements are on the order of hundreds of micrometres. In the biochronology literature, the number of times increment widths are measured is variable, ranging from once (e.g. Black et al., 2005; Doubleday et al., 2015; Roberts et al., 2019), twice (e.g. Black et al., 2011; Gillanders et al., 2012), to three or more replicate measurements (e.g. Coulson et al., 2014; Herdter, 2014; Nguyen et al., 2015; Ong et al., 2015) which are then averaged prior to analysis. We adopted stringent quality control measures to maximise the precision (i.e. repeatability as per Chilton \& Beamish, 1982) of increment width measurements. Measurements were taken twice by a single reader in separate measuring sessions. If the difference between the first and second measurement sessions for each of the three increments of any given otolith was $\leq 15 \%$, then the final value of each increment width was calculated as the mean of the two measuring sessions. If any increment widths differed by $>15 \%$ between the two measuring sessions, then the otolith was measured a third time. As above, where the difference between the first and third session for each of the three increments was $\leq 15 \%$, the value of each increment width was calculated as the mean of the first and third measuring sessions, and similarly for agreement between the second and third measuring sessions. Finally, if the measurements of any increments differed by $>15 \%$ between all three combinations of measuring sessions, then the otolith was excluded from the dataset $(\mathrm{N}=2, \mathrm{~N}=6$, and $\mathrm{N}=7$ samples removed from the Mitchell, Gilbert, and Flinders datasets, respectively). This quality control procedure resulted in an increment width dataset of 332 individuals in the Mitchell region, 295 individuals in the Gilbert region, and 863 individuals in the Flinders region (Table 1). 
Table 1 Details of the otolith dataset used to build statistical models for each region

\begin{tabular}{|c|c|c|c|c|}
\hline & Mitchell & Gilbert & Flinders & Total \\
\hline Total number of otoliths measured & 334 & 301 & 870 & 1,505 \\
\hline $\begin{array}{l}\text { Total number of otoliths retained after quality control (consensus) } \\
\text { procedure }\end{array}$ & 332 & 295 & 863 & 1,490 \\
\hline Growth years represented by $>10$ increment measurements & 1997 to 2009 & 2006 to 2013 & 1997 to 2014 & \\
\hline Total number of otoliths retained after removing data-sparse years & 325 & 283 & 860 & 1,468 \\
\hline $\begin{array}{l}\text { Total number of otoliths retained after removing statistical } \\
\text { outliers }\end{array}$ & 324 & 282 & 859 & 1,465 \\
\hline Total number of increment measurements used in growth models & 935 & 825 & 2,320 & 4,080 \\
\hline Mean (and range) of decimal age-at-capture & $\begin{array}{c}4.73(2.33 \text { to } \\
10.00)\end{array}$ & $\begin{array}{l}4.82(2.33 \text { to } \\
10.33)\end{array}$ & $\begin{array}{l}4.04(2.00 \text { to } \\
11.33)\end{array}$ & \\
\hline
\end{tabular}

Environmental data collection

\section{Water availability}

The focal metric for the current study is river discharge (GL per quarter), which refers to both volume and seasonal timing (i.e. hydrology) of flows. There is strong evidence that physical characteristics (i.e. hydraulics) of freshwater flows are also important to the growth and survival of fish (Mallen-Cooper \& Zampatti, 2018, 2020). However, the hydraulic aspects of river flows are beyond the scope of this study, and a time-series of such data are not available for the study catchments.

Modelled daily End of System (EOS) river discharge (ML, i.e. $10^{6} \mathrm{~L}$, per day) was retrieved from the Commonwealth Scientific and Industrial Research Organisation (CSIRO) Northern Australia Water Resources Assessment (NAWRA) River Model App (https://nawra-river.shinyapps.io/river/, node 9190000, Hughes et al., 2017) for the Mitchell River. Modelled daily EOS river discharge was available for the Gilbert and Flinders river systems from the Queensland Department of Environment and Science (Queensland Hydrology, unpublished data). These hydrodynamic models are designed for scenario testing of water development planning in each region, and provide simulated river discharge at continuous daily time steps under a range of water extraction scenarios. The modelled daily river discharge volumes used in the current study incorporate historical and current water extraction activities in each region.
River discharge data were reclassified from calendar years to hydrological years, which begin in October and end in September and are enumerated by the calendar year value in January (i.e. the hydrological year from October 1995 to September 1996 is referred to as "1996"). Hydrological years are better aligned with seasonal patterns in barramundi growth rates than are calendar years (Xiao, 1999). River discharge in July, August and September was minimal or absent for all study years (1997 to 2014) and regions, with the exception of a single small pulse flood event in the Flinders River in July 2007. July, August, and September were therefore excluded from further analyses. Total river discharge was summed by quarter, with discharge in October-November-December representing an early start to the northern wet season, January-February-March capturing the peak wet season flows and April-May-June capturing a late end to the northern wet season, as well as the natural end-of-season draining of each catchment. River discharge is reported in GL $\left(10^{9} \mathrm{~L}\right)$ per quarter (three-month period) unless otherwise specified. Total discharge in each quarter was natural log transformed to improve variable distribution.

Alternative discharge variables, as well as temperature variables, were developed and tested but were not used in the models presented here (Supplementary Material 3). Juvenile barramundi growth rates are likely influenced by a number of factors not addressed in this project, including water temperature, prey availability, competition, and risk of predation. However, historical data for each of these variables in the Gulf of Carpentaria region is extremely limited. 
Furthermore, many of these variables are likely to be strongly collinear, with wet season flooding coinciding with warm summer temperatures, and resulting in wetland inundation that is likely to dramatically increase food availability. Therefore, total river discharge in each quarter for each region was used as the best available historical proxy for environmental conditions affecting juvenile barramundi growth rates, while also being the most relevant metric for planned water resource development.

\section{Atmospheric indices}

The Southern Oscillation Index (SOI) is an indicator of El Niño Southern Oscillation (ENSO), an important ocean-atmosphere process in the tropical Pacific Ocean moderated by sea surface temperature and atmospheric pressure, and associated with changes in precipitation patterns and wind strength across the tropical Pacific. Sustained negative values of SOI $<-8$ are indicative of El Niño events which are associated with hotter and drier than normal conditions in northern Australia. Sustained positive SOI values $>8$ are indicative of La Niña events, which are associated with cooler and wetter than normal conditions in northern Australia (Bureau of Meteorology, 2012b). Although SOI values can be indicative of ENSO climate events, the unpredictable paths of cyclones in the Gulf of Carpentaria can produce large rainfall events in coastal catchments that are not aligned with SOI values or ENSO events. Monthly SOI values were retrieved from the Australian Bureau of Meteorology (bom.gov.au/climate/current/soiht$\mathrm{m} 1$.shtml). Monthly SOI data were aligned to hydrological years, and monthly SOI values between October and March ( $\cong$ austral summer) were averaged to provide an annual metric of SOI for analysis against juvenile barramundi growth.

The Madden-Julian Oscillation (MJO) describes an eastward moving body of moist air that results in locally increased sub-equatorial cloud cover and rainfall in a 30-60 day recurring cycle (Madden \& Julian, 1972). The MJO has been linked to climate, wind, and oceanographic conditions in the Gulf of Carpentaria preceding and during the Australian monsoon season (Oliver \& Thompson, 2012). Phases 4 and 5 of the MJO capture the intensity of the MJOrelated enhanced convective activity over the Gulf of Carpentaria region (Wheeler \& Hendon, 2004). MJO intensity values in the Phase 4 region (centred on $140^{\circ}$ East) were available every five days from the United States National Weather Service (https://www.cpc. ncep.noaa.gov/products/precip/CWlink/daily_mjo_ index/pentad.html). MJO values were averaged within a shorter wet season period (January to March) to provide an index of MJO intensity during the peak wet season quarter (defined above).

Other atmospheric indices known to affect the Gulf of Carpentaria (e.g. Australian Monsoon Index, Pacific Decadal Oscillation) are not presented here as they displayed strong statistical collinearity with SOI during the study period, and could therefore not be distinguished from the influence of SOI.

Growth rate modelling

A Gamma generalised linear mixed-effects model (GLMM) with a log link function was used to test the hypothesis that otolith increment widths in juvenile barramundi were influenced by quarterly river discharge (Eq. 1). Fixed covariates were increment number (categorical with three levels), total river discharge in October, November, and December ( $\mathrm{D}_{\mathrm{OND}}$, continuous), total river discharge in January, February, and March ( $\mathrm{D}_{\mathrm{JFM}}$, continuous), total river discharge in April, May, and June ( $\mathrm{D}_{\mathrm{AMJ}}$, continuous), and age-at-capture (continuous). Age-at-capture (as decimal age) was included as a covariate to account for any age selectivity in the samples (Morrongiello et al., 2012). This model term accounts for potential bias in the dataset, possible in a size-selective fishery, in which individuals with rapid or slow growth trajectories recruit to the fishery and occur in the dataset at disproportionately younger or older ages, respectively (i.e. the Rosa Lee phenomenon), potentially skewing growth rate reconstructions (Morrongiello et al., 2012). To incorporate dependency among measurements from the same fish, we used FishID as a random intercept. The model specification for the Gamma GLM using river discharge variables is:

$$
\begin{aligned}
& \text { width }_{i j} \sim \operatorname{Gamma}\left(\mu_{i j}, v\right) \\
& E\left(\text { width }_{i j}\right)=\mu_{i j} \text { and } \operatorname{var}\left(\text { width }_{i j}\right)=\frac{\mu_{i j}^{2}}{v}
\end{aligned}
$$




$$
\begin{aligned}
\log \left(\mu_{i j}\right)= & \alpha_{0}+\text { Inc }_{i j}+D_{O N D_{i j}}+D_{J F M_{i j}}+D_{A M J_{i j}} \\
& + \text { AgeAtCapture }_{i j}+\text { FishID }_{i}
\end{aligned}
$$

where width is the $j$ th measured increment width for individual fish $i$ and FishID $_{i}$ is the random intercept, which is assumed to be normally distributed with mean 0 and variance $\sigma^{2}$. The $v$ term is analogous to the dispersion parameter $k$ in a negative binomial distribution (Zuur et al., 2009), $\alpha_{0}$ is the model intercept, and $I n c$ stands for increment number.

A separate Gamma GLMM with a log link function was used to test the hypothesis that atmospheric indices could be used instead of river discharge to model otolith increment widths. Fixed covariates were increment number (categorical with three levels), SOI (continuous), MJO (continuous), and age-at-capture (continuous). To incorporate the dependency among measurements from the same fish, we used FishID as a random intercept. The model specification for the Gamma GLM using atmospheric indices is:

width $_{i j} \sim \operatorname{Gamma}\left(\mu_{i j}, v\right)$

$$
\begin{aligned}
E\left(\text { width }_{i j}\right)=\mu_{i j} \text { and } \operatorname{var}\left(\text { width }_{i j}\right)=\frac{\mu_{i j}^{2}}{v} \\
\begin{aligned}
\log \left(\mu_{i j}\right)= & \alpha_{0}+\text { Inc }_{i j}+\text { SOI }_{i j}+\text { MJO }_{i j} \\
& + \text { AgeAt Capture }_{i j}+\text { Fish ID }_{i}
\end{aligned}
\end{aligned}
$$

where width is the $j$ th measured increment width for individual fish $i$ and FishID $_{i}$ is the random intercept, which is assumed to be normally distributed with mean 0 and variance $\sigma^{2}$.

Important differences in flow regime (Kennard et al., 2010) and total discharge volumes (Fig. 2) among the focal catchments made it inappropriate to pool the regions into a single model with "region" as a covariate or random effect. Furthermore, interpretation of model coefficient outputs for water development scenarios and extension of results to water development planning would be made unnecessarily complex by the addition of multiple two-way interactions with a region factor. Therefore, separate models were built for each region.

All GLMMs were implemented using integrated nested Laplace approximation (INLA) for Bayesian inference in R-INLA (Rue et al., 2009; Martins et al., 2012) using default priors for FishID random effects.
Only growth years which were represented by $>10$ increment measurements were included in analyses (Table 1, Supplementary Material 4), as recommended by Smoliński et al. (2020) for representative sample sizes in biochronological studies. Predictor variables were inspected for data range, distribution, and collinearity, and outliers in the response variable were removed ( $\mathrm{N}=1$ outlier per region) prior to inclusion in the models. River discharge in October-NovemberDecember in the Gilbert River and river discharge in April-May-June in the Flinders River were excluded from models due to high collinearity with JanuaryFebruary-March discharge in each region $(r>0.60$, Dormann et al., 2013; Zuur et al., 2013). All continuous predictor variables were standardized using the scale function in the base $\mathrm{R}$ package to have a mean of zero and a standard deviation of one to assist interpretation and comparison of model coefficients. River discharge variables were selected a priori for inclusion based on their relevance to water development planning, while atmospheric indices were selected to facilitate model incorporation into future climate-based forecasting. Variable reduction methods or model selection procedures were therefore not applied.

Water development scenario testing

Multiple hypothetical water development scenarios have been proposed for the Mitchell, Gilbert, and Flinders rivers to inform water resource and agricultural development planning in northern Australia (Hughes et al., 2017; Petheram et al., 2018a, b; Pollino et al., 2018; Broadley et al., 2020; Burford et al., 2020). These represent a range of surface water allocations and utilisation, surface water harvesting via pumping or instream dams, and different thresholds for minimum instream discharge levels prior to beginning harvesting ("pump start threshold"). In the current study, the effect of three different water development scenarios on juvenile barramundi growth rates were explored for the Mitchell River, representing a range of high, medium, and low extraction development proposals (Table 2). Daily timeseries of river discharge for the Mitchell River under each scenario were generated by the NAWRA River Model App (https://nawra-river.shinyapps.io/river/). The effect of modified flow scenarios on juvenile barramundi growth rates was not explored for the Gilbert 
Fig. 2 Total river discharge (in GL) in early (OctoberNovember-December), mid (January-February-March), and late (April-May-June) wet season in a the Mitchell, b the Gilbert, and $\mathbf{c}$ the Flinders region, and d SOI and e MJO summer intensities. Dashed lines in d indicate the threshold for La Niña $(>+8)$ and El Niño $(<-8)$ phases of SOI. Grey shaded areas in a through $\mathbf{c}$ indicate which years contained sufficient otolith increment data to be included in growth models. Variable calculations are described in-text

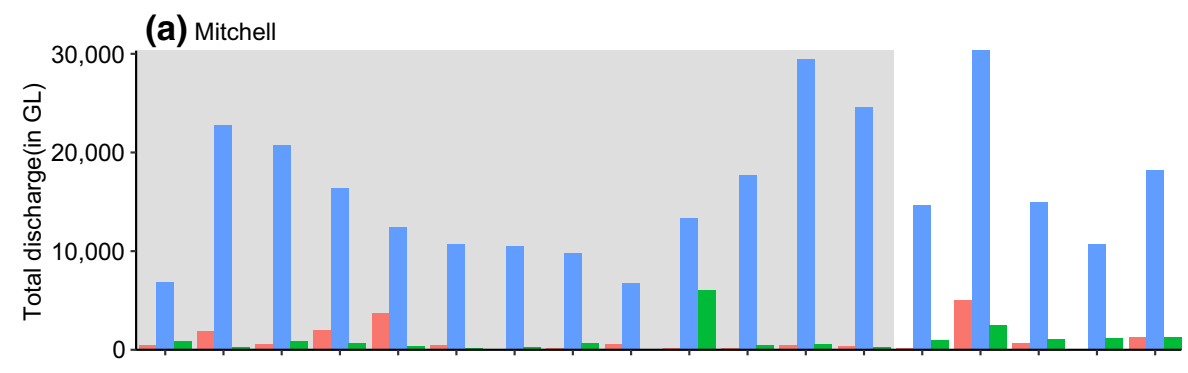

(b) Gilbert

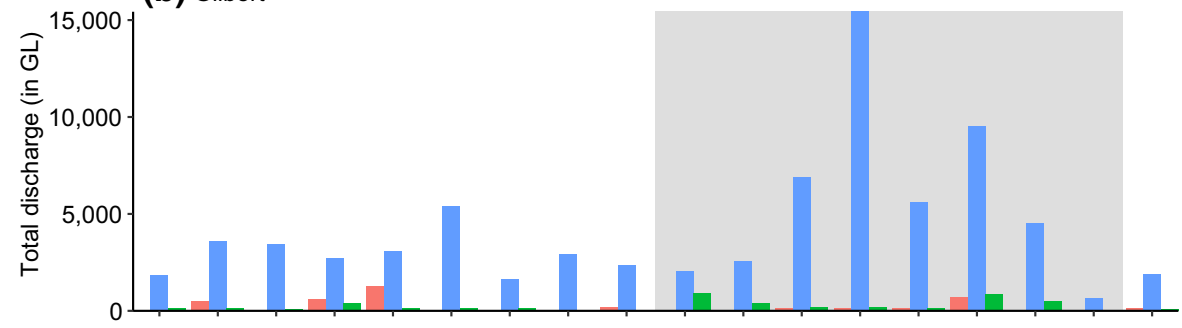

(c) Flinders
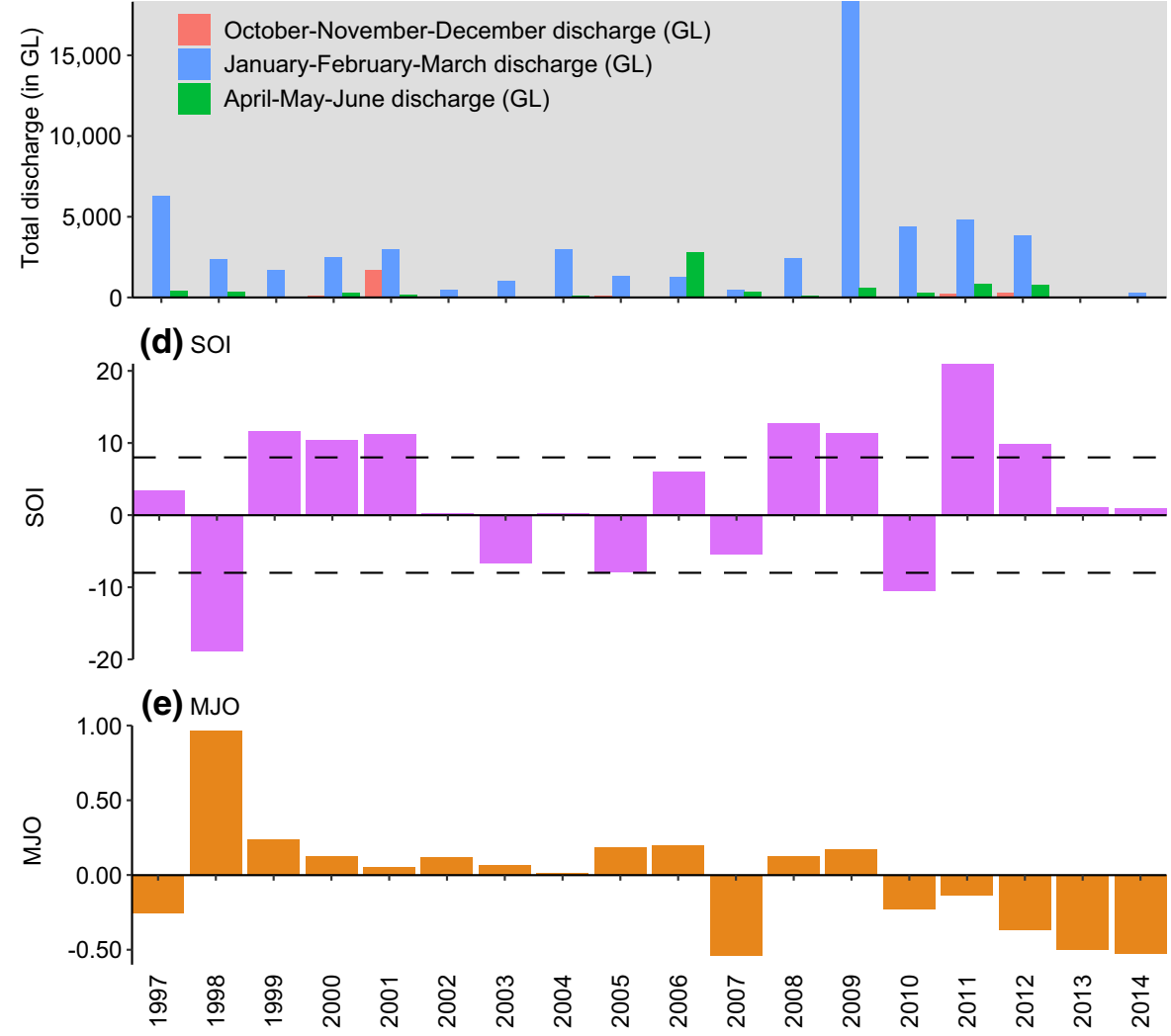

and Flinders rivers, as timeseries of daily river discharge for each development scenario did not coincide with the full period for which otolith increment width data were available. For the Mitchell River water development scenarios, total river discharge was summed by quarter (October-November-December, January-February-March, and April-May-June) for each hydrological year, natural log transformed, and scaled and centred using the mean and standard deviation of the base scenario over the period for 
Table 2 Water development scenarios used to model the effect of changes in river flows on otolith increment widths of juvenile barramundi in the Mitchell region

\begin{tabular}{lll}
\hline Scenario & Description & Mean annual flow reduction \\
\hline Base case & Current allocations and usage & $0 \%$ \\
High extraction & Construction of multiple major in-stream dams (Chillagoe, & $18 \%$ \\
& Nullinga, Pinnacles, Rookwood, and Palmer River dams) & \\
& No additional surface water harvest & $8 \%$ \\
Medium extraction & No dam construction & \\
& Surface water harvest, maximum 200 GL/year at each of & \\
& three nodes (9190092, 9193090, 9190090) & $3 \%$ \\
Low extraction & High pump start threshold (1,800 ML/day) & \\
\hline
\end{tabular}

which matching otolith data were available (Table 1). We then used the fitted Bayesian model for the Mitchell River to predict median otolith increment widths under each water development scenario.

\section{Results}

Timing of increment formation

Across all study regions, 1,490 otoliths were assessed for increment count and edge formation and retained after quality control procedures (Table 1). The formation of a new opaque band (i.e. narrow edge type, classified as "newly formed") was observed as early as February in 5.8\% of fish sampled from that month (Fig. 3), all of which were from the Flinders region, which has the highest latitude $\left(\sim 17.5^{\circ} \mathrm{S}\right.$, Fig. 1). Narrow edge types became increasingly common over the following months. By September (at the end of the austral winter), more than $60 \%$ of fish were classified as having a narrow edge type (i.e. recent opaque band formation and corresponding slow growth (Fig. 3a).

A potential latitudinal gradient appeared once samples were separated by region (Fig. 3b-d), although this may be influenced by the unequal and/ or low sample numbers available from each region in each month. The formation of a new opaque band was observed earliest at the highest latitude region (February in the Flinders, Fig. 3d, Fig. 1), a month later at the intermediate region (Gilbert, Fig. 3c), and not until another month later at the lowest latitude region (Mitchell, Fig. 3b). Similarly, more than $50 \%$ of fish displayed a new increment by June in the southernmost Flinders region, by July in the intermediate Gilbert region, and by September in the northernmost Mitchell region (Fig. 3b-d).

River and atmospheric index patterns

Peak river discharge occurred during the JanuaryFebruary-March quarter in all study regions and hydrological years, with the exception of the Flinders region in 2006 (Fig. 2). Quarterly and total End of System (EOS) modelled discharge was highly variable across the study years, but was consistently highest for the Mitchell River (Fig. 2a) as compared to the Gilbert and Flinders rivers (Fig. 2b and c).

Mean summer SOI across the study period (Fig. 2d) captured well-known ENSO events, e.g. 1998 El Niño summer, 2011 and 2012 La Niña summers (Bureau of Meteorology, 2012b). SOI was typically positively associated with log-transformed early, mid, and late wet season river discharge in all study regions $(0.19<\mathrm{r}<0.46)$, although the correlations were non-significant $(P \geq 0.20)$. SOI demonstrated a small negative non-significant correlation with $\mathrm{MJO}$ across the study period $(r=-0.21, P>0.05)$, which is within the observed range of the highly variable relationship between MJO and ENSO processes (McPhaden et al., 2006; Hendon et al., 2007).

Mean MJO intensity during the peak wet season quarter (January-February-March) ranged from - 
(a) All Regions

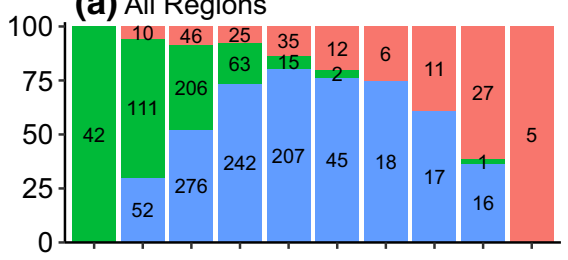

(b) Mitchell

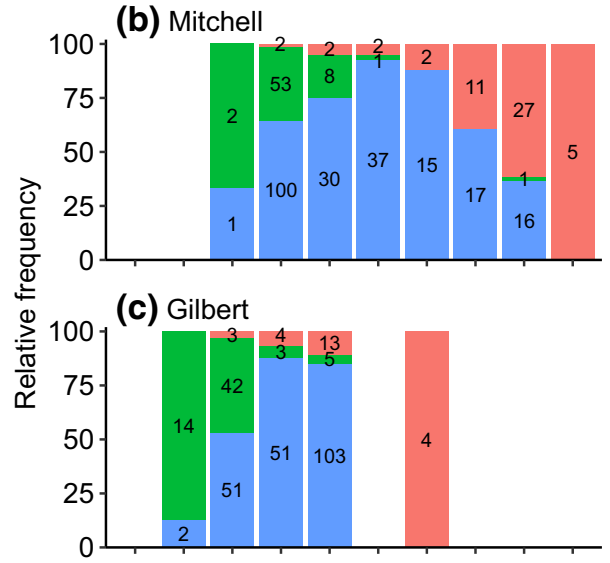

(d) Flinders

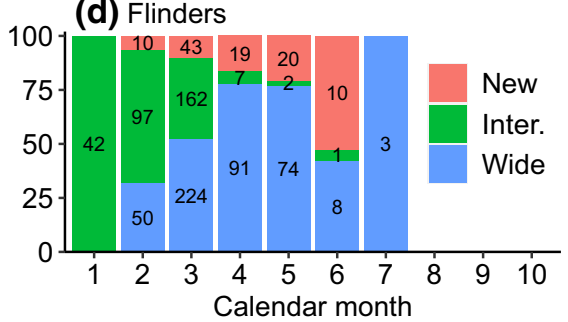

Fig. 3 Otolith edge type frequency histogram indicating relative frequency of edge types (newly formed, intermediate, or wide, as per Fisheries Queensland (2012)) across the calendar year for a the full dataset, b Mitchell region, $\mathbf{c}$ Gilbert region, and d Flinders region. Samples are sparse in October and unavailable in November and December due to seasonal closure of the fishery from 7 October to 1 February each year. Samples collected in January in the Flinders region are from research activities

0.53 (in 2007) to 0.96 (in 1998) (Fig. 2e). MJO was generally positively associated with log-transformed river discharge during the peak wet season quarter in all regions $(0.32<r<0.54)$, although these correlations were non-significant $(P>0.05)$.

\section{Drivers of otolith increment width}

A total of 4080 increment widths were used to determine the influence of environmental factors on growth rates of juvenile barramundi. Increment number and age-at-capture were identified as important variables (analogous to frequentist statistical significance) in both river discharge and atmospheric index models in all three regions (Table 3). As expected, increment number had the strongest effect on increment width by an order of magnitude, due to the decline in growth rates with age (Stuart \& McKillup, 2002). A weaker negative effect of the age-at-capture covariate indicated that individuals captured at an older age had narrower early growth increments (i.e. slower growers were captured older) than fish captured at a younger age (i.e. faster growers were captured younger).

\section{Mitchell region}

Results from the Gamma GLMM indicate that early (October-November-December), peak (January-February-March), and late (April-May-June) wet season river discharge are important determinants of otolith increment widths in juvenile barramundi in the Mitchell region (Table 3). Larger discharge volumes at any time during the hydrological year resulted in larger otolith increment widths (Table 3, Fig. 4a-c). Atmospheric indices, in particular SOI, were also important determinants of otolith increment widths, with the largest otolith increment widths observed in La Niña (strongly positive SOI) and intensely monsoonal (high MJO) years (Table 3, Fig. 4d and e). The $\mathrm{R}^{2}$ for both the river discharge and climactic models was 0.90 .

\section{Gilbert region}

Peak (January-February-March) and late (AprilMay-June) wet season river discharge were important determinants of otolith increment widths in juvenile barramundi in the Gilbert region (Table 3). Larger discharge volumes in the peak and late wet season resulted in significantly larger otolith increment widths (Table 3, Fig. 4f, g), noting that early wet season river discharge (October-November-December) was excluded from analyses due to strong collinearity with peak wet season discharge.

SOI was an important determinant of otolith increment width in the atmospheric model, with larger otolith increment widths observed in La Niña (strongly positive SOI) years (Table 3, Fig. 4h). MJO was not identified as an important variable in the Gilbert region (Fig. 4i), potentially due to the low 
Table 3 Posterior means and credible intervals (0.025 and 0.975 quantiles) for the river discharge and atmospheric indices-mixed effects models for each region; the response variable is otolith increment width, a proxy for somatic growth rate. Random intercept effect of FishID was included in all models. River discharge and age-atcapture variables were natural log-transformed continuous predictor variables were scaled and centred prior to analysis. Posterior distributions of increments 2 and 3 are relative to increment 1 prior to analysis, and all
*Denotes variable importance, i.e. the $95 \%$ credible interval for the variable's posterior distribution does not include zero. This is equivalent to a frequentist threshold of $P<0.05$ statistical significance

\begin{tabular}{|c|c|c|c|c|c|c|}
\hline Region & Model & Predictor & Q 0.025 & Mean & Q 0.975 & Model $\mathrm{R}^{2}$ \\
\hline \multirow[t]{13}{*}{ Mitchell } & \multirow[t]{7}{*}{ River discharge } & Intercept & -0.679 & $-0.665^{*}$ & -0.651 & \multirow[t]{7}{*}{0.897} \\
\hline & & Age-at-capture & -0.042 & $-0.033^{*}$ & -0.024 & \\
\hline & & Increment 2 & -0.525 & $-0.507 *$ & -0.489 & \\
\hline & & Increment 3 & -0.813 & $-0.794 *$ & -0.775 & \\
\hline & & $\mathrm{D}_{\mathrm{OND}}$ & 0.007 & $0.016^{*}$ & 0.025 & \\
\hline & & $\mathrm{D}_{\mathrm{JFM}}$ & 0.001 & $0.010^{*}$ & 0.019 & \\
\hline & & $\mathrm{D}_{\mathrm{AMJ}}$ & 0.003 & $0.011^{*}$ & 0.020 & \\
\hline & \multirow[t]{6}{*}{ Atmospheric } & Intercept & -0.677 & $-0.664 *$ & -0.650 & \multirow[t]{6}{*}{0.902} \\
\hline & & Age-at-capture & -0.044 & $-0.035^{*}$ & -0.026 & \\
\hline & & Increment 2 & -0.528 & $-0.510^{*}$ & -0.492 & \\
\hline & & Increment 3 & -0.815 & $-0.797 *$ & -0.778 & \\
\hline & & SOI & 0.014 & $0.022 *$ & 0.030 & \\
\hline & & MJO & 0.009 & $0.017 *$ & 0.025 & \\
\hline \multirow[t]{12}{*}{ Gilbert } & \multirow[t]{6}{*}{ River discharge } & Intercept & -0.759 & $-0.742 *$ & -0.725 & \multirow[t]{6}{*}{0.868} \\
\hline & & Age-at-capture & -0.033 & $-0.022 *$ & -0.011 & \\
\hline & & Increment 2 & -0.448 & $-0.426^{*}$ & -0.404 & \\
\hline & & Increment 3 & -0.748 & $-0.723^{*}$ & -0.698 & \\
\hline & & $\mathrm{D}_{\mathrm{JFM}}$ & 0.015 & $0.025^{*}$ & 0.036 & \\
\hline & & $\mathrm{D}_{\mathrm{AMJ}}$ & 0.007 & $0.019 *$ & 0.031 & \\
\hline & \multirow[t]{6}{*}{ Atmospheric } & Intercept & -0.749 & $-0.733^{*}$ & -0.716 & \multirow[t]{6}{*}{0.860} \\
\hline & & Age-at-capture & -0.032 & $-0.021^{*}$ & -0.010 & \\
\hline & & Increment 2 & -0.450 & $-0.428^{*}$ & -0.406 & \\
\hline & & Increment 3 & -0.770 & $-0.748^{*}$ & -0.725 & \\
\hline & & SOI & 0.002 & $0.013 *$ & 0.025 & \\
\hline & & MJO & -0.011 & 0.000 & 0.012 & \\
\hline \multirow[t]{12}{*}{ Flinders } & \multirow[t]{6}{*}{ River discharge } & Intercept & -0.723 & $-0.715^{*}$ & -0.706 & \multirow[t]{6}{*}{0.875} \\
\hline & & Age-at-capture & -0.028 & $-0.022 *$ & -0.016 & \\
\hline & & Increment 2 & -0.487 & $-0.475^{*}$ & -0.463 & \\
\hline & & Increment 3 & -0.826 & $-0.812 *$ & -0.798 & \\
\hline & & $\mathrm{D}_{\mathrm{OND}}$ & 0.005 & $0.010 *$ & 0.016 & \\
\hline & & $\mathrm{D}_{\mathrm{JFM}}$ & 0.018 & $0.024 *$ & 0.030 & \\
\hline & \multirow[t]{6}{*}{ Atmospheric } & Intercept & -0.724 & $-0.715^{*}$ & -0.706 & \multirow[t]{6}{*}{0.873} \\
\hline & & Age-at-capture & -0.028 & $-0.022 *$ & -0.016 & \\
\hline & & Increment 2 & -0.478 & $-0.465^{*}$ & -0.453 & \\
\hline & & Increment 3 & -0.837 & $-0.823 *$ & -0.809 & \\
\hline & & SOI & 0.010 & $0.015^{*}$ & 0.021 & \\
\hline & & MJO & -0.002 & 0.004 & 0.010 & \\
\hline
\end{tabular}

\section{Flinders region}

variability in MJO values recorded during years for which sufficient otolith increment data were available (2006 to 2013, Table 1, Figs. 2 and 4i).
Early (October-November-December) and peak (January-February-March) wet season river discharge were important determinants of otolith increment widths in juvenile barramundi in the Flinders region (Table 3). Larger discharge volumes at these times of 
Mitchell

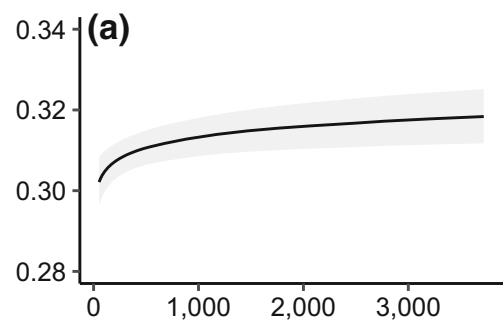

Gilbert

Excluded due to collinearity with discharge in Jan-Feb-Mar
Flinders

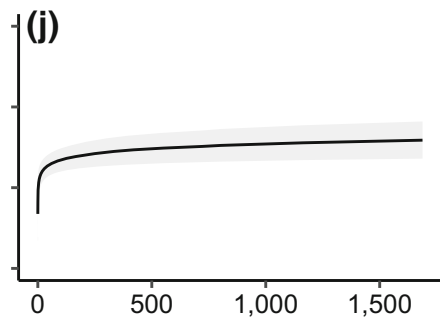

Total river discharge in Oct-Nov-Dec (in GL)
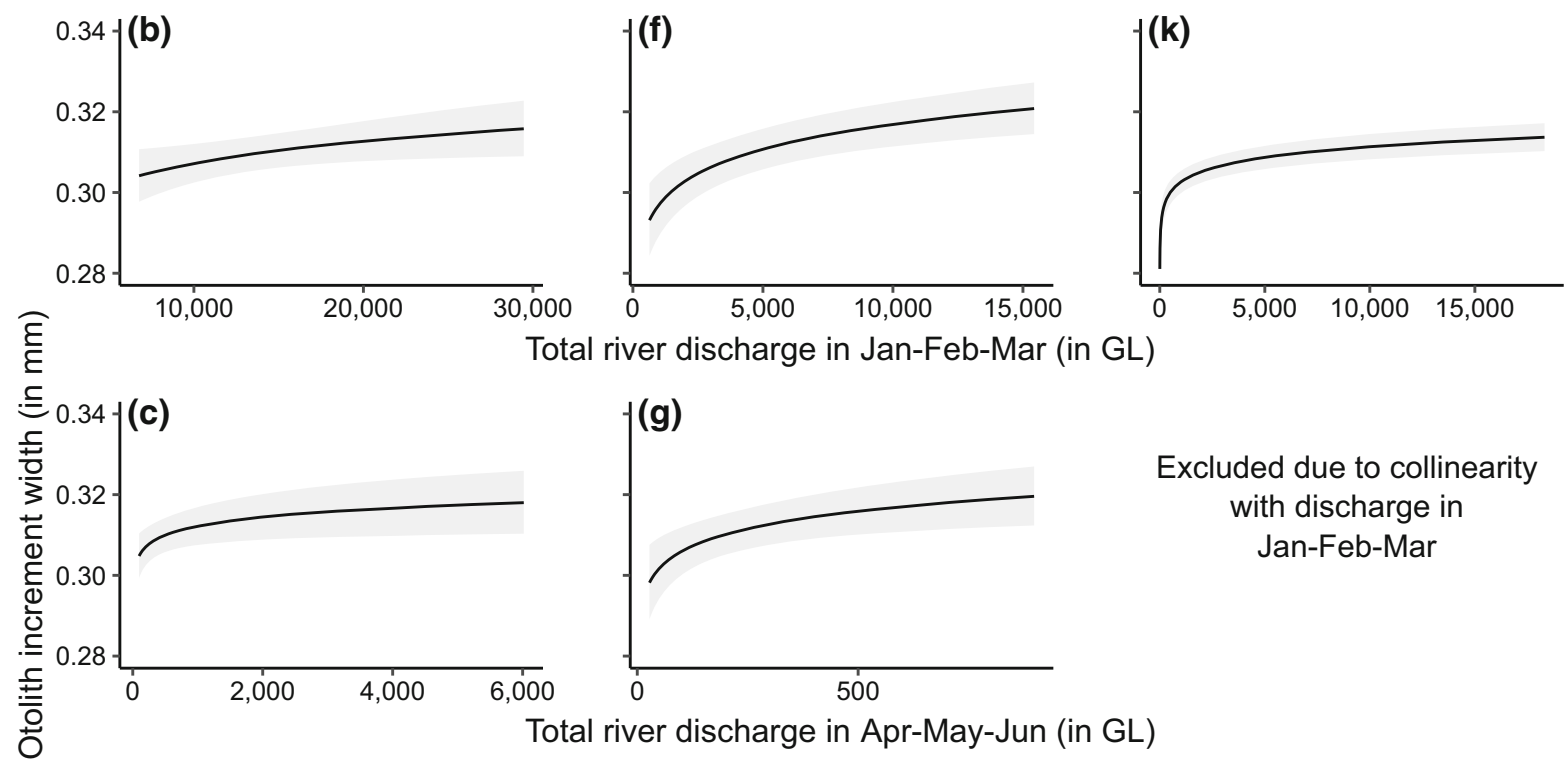

otal river discharge in Jan-Feb-Mar (in GL)
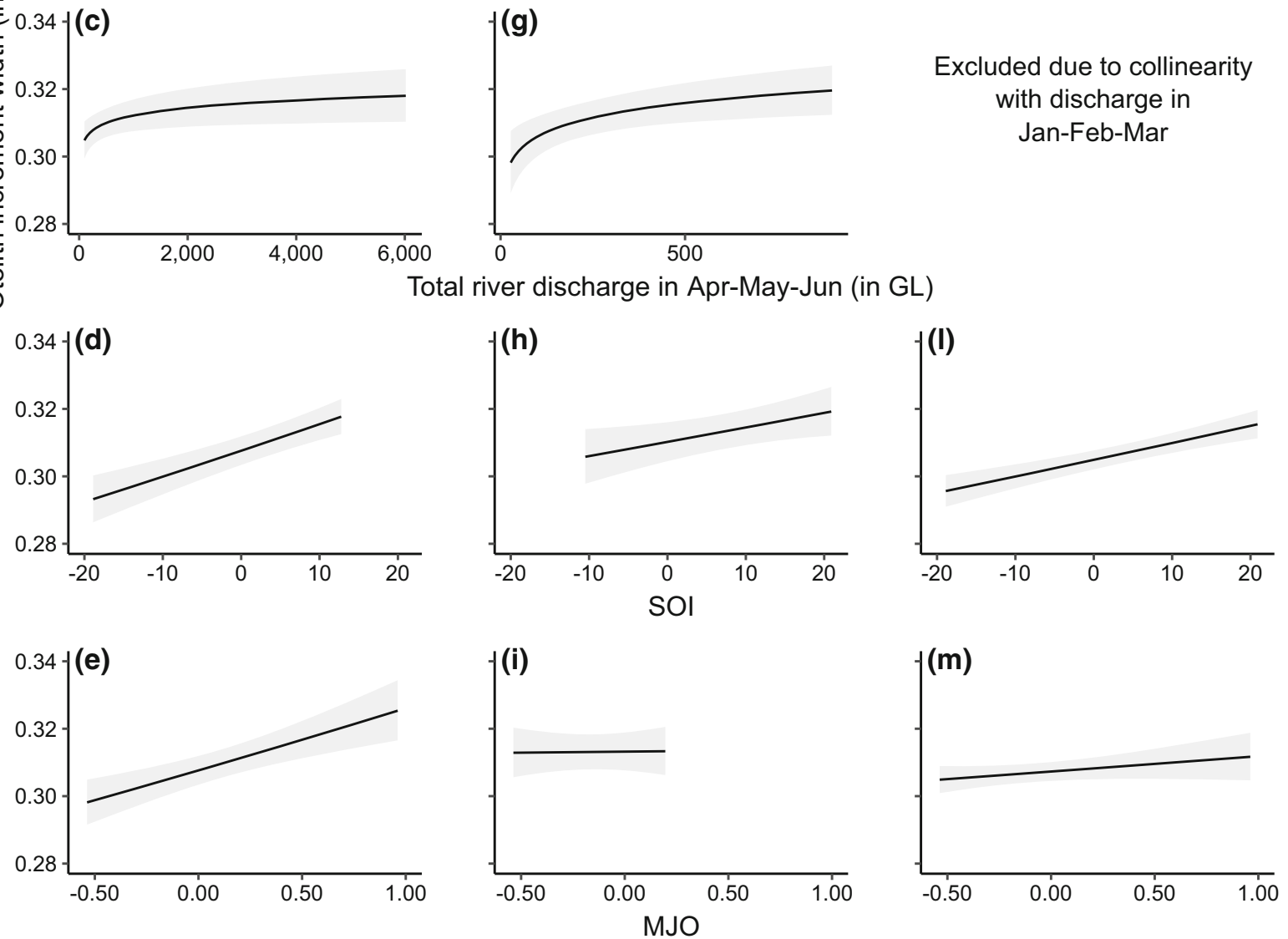

Fig. 4 Predicted otolith increment width (with 95\% credible intervals) as a function of freshwater discharge and atmospheric variables for the Mitchell River ((a) through (e)), the Gilbert
River ((f) through (i)), and the Flinders River ((j) through (m)). Note: all $y$-axes have matching ranges, but $\mathrm{x}$-axis ranges for river discharge panels vary by region and time of year 
year resulted in significantly larger otolith increment widths, but with much more distinct and abrupt flattening of the logarithmic relationship between river discharge and increment width than was observed for the Mitchell or Gilbert regions (Fig. 4). The greatest effect of early wet season discharge occurred below approximately 500 GL (Fig. 4j). The greatest effect of peak wet season discharge occurred below approximately 7500 GL (Fig. 4k). This likely reflects the more frequent occurrence of seasonal discharge volumes below these thresholds. Discharge in excess of 500 GL in the early wet season quarter, and in excess of $7500 \mathrm{GL}$ in the peak wet season quarter were recorded just once during the 18-year study period (Fig. 2c). These single occurrences are therefore responsible for the long flat "tail" of the modelled relationship for the Flinders region. River discharge in the late wet season was excluded from analyses due to strong collinearity with peak wet season discharge.

SOI was an important determinant of otolith increment width in the atmospheric model, with larger otolith increment widths observed in La Niña (strongly positive SOI) years (Fig. 41). MJO demonstrated a weak positive relationship with otolith increment width in the Flinders region, but did not attain the threshold for statistical importance (Table 3, Fig. 4m).

\section{Water development scenario testing}

Wet season End-Of-System (EOS) discharge from the Mitchell River was reduced by $18 \%, 8 \%$, and $3 \%$ under the hypothetical high, medium, and low extraction water development scenarios compared with existing flow conditions (Table 2). In all three scenarios, the majority of water extraction, by volume, occurred during the peak of the wet season (JanuaryFebruary-March, Fig. 5a). However, the smaller volume of water harvested early (October-NovemberDecember) and late (April-May-June) in the wet season represented a much larger percentage reduction in discharge during those quarters (Fig. 5a and b).

The Bayesian Gamma GLMM predicted that otolith increment widths (and thus annual juvenile barramundi growth rates) in the Mitchell region would be reduced by $12.7 \%$ (range: 11.6 to $13.8 \%$ ), $6.7 \%$ (range: 6.5 to $6.9 \%$ ), and $1.25 \%$ (range: 1.25 to $1.26 \%$ ) under the hypothetical high, medium, and low
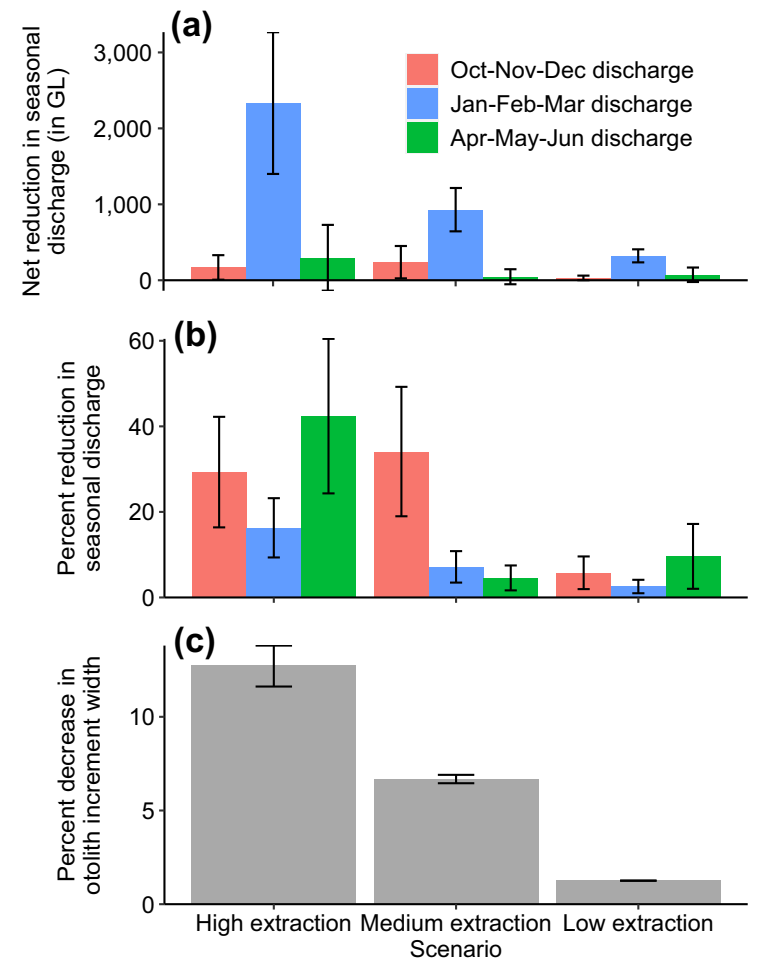

Fig. 5 Reduction in a net seasonal river discharge (mean \pm $\mathrm{SE})$ and $\mathbf{b}$ percent seasonal river discharge (mean $\pm \mathrm{SE}$ ) relative to base (existing) water harvesting conditions for each water harvesting scenario described in Table 2. c Reduction in median otolith increment widths under each water harvesting scenario relative to the range of otolith increment widths observed under base scenario conditions

extraction water development scenarios compared with existing flow conditions (Table 2, Fig. 5). Although all three wet season quarters were important contributors to otolith increment widths in the Mitchell region (Table 3), the predicted reductions in growth rate under each water development scenario appear to be approximately proportional to the reduction in percent river discharge in the peak wet season quarter (January-February-March, Fig. 5b and c).

\section{Discussion}

In this study, we successfully quantified the effect of wet season river discharge on the first three otolith increment widths of barramundi in three rivers in the Gulf of Carpentaria with differing flow regimes. Models were also developed which incorporated the Southern Oscillation Index and the Madden-Julian 
Oscillation, and indicated that SOI values corresponding to La Niña events had strong positive consequences for juvenile barramundi growth rates in all regions. The river discharge model for the Mitchell region was used to estimate the relative impact of three hypothetical water development scenarios on growth rates of juvenile barramundi. The model predicted a $12 \%, 8 \%$ and $1 \%$ reduction in annual barramundi growth rates under proposed scenarios for $18 \%, 8 \%$, and $3 \%$ reduction in river discharge, respectively. We also used otolith marginal increment analysis to identify the timing of opaque band formation and confirm annuli deposition for Gulf of Carpentaria barramundi.

\section{Timing of increment formation}

Marginal increment analysis supports the inference that opaque bands in barramundi otoliths are formed annually in the Gulf of Carpentaria. The timing of opaque band formation (February/April through to October, Fig. 3) is consistent with the timing of formation of scale checks in barramundi in the southern Gulf of Carpentaria (Davis \& Kirkwood, 1984), the formation of otolith opaque bands in barramundi reported on Queensland's east coast (Stuart \& McKillup, 2002; Staunton-Smith et al., 2004), and with modelled reductions in barramundi growth rates during the austral winter (Xiao, 1999). A potential latitudinal gradient in the onset of new opaque band formation may be related to the earlier onset of slow growth conditions (i.e. lower temperatures) at higher latitudes (Flinders region, approx. $17.5^{\circ} \mathrm{S}$, Fig. 1).

Flow drivers of otolith increment width

The current study has quantified the importance of wet season river discharge on the first three increment widths of barramundi in three catchments. These catchments currently have relatively minor water resource development, but are focal areas for agricultural and water resource development in Northern Australia (FGARA, Holz et al., 2013; NAWRA, Petheram et al., 2018b). In the Gilbert and Flinders regions, which experience highly intermittent seasonal river flows of just 150 to 250 days per year (Kennard et al., 2010), the most influential wet season period was the peak of the wet season (January-December-
March), although this effect may be amplified by the removal of collinear wet season periods from the mixed-models i.e. October-November-December in the Gilbert region and April-May-June in the Flinders region. Conversely, in the Mitchell River which is typically perennial, with low but consistent base flow and summer dominant flows (Kennard et al., 2010), all three wet season quarters had similar magnitude effects on barramundi growth rates (Table 3). The more extended flow regime in the Mitchell River potentially enables greater upstream access and greater longevity of seasonally ephemeral wetlands (Ndehedehe et al., 2021), possibly enabling extended periods of growth in juvenile barramundi in the Mitchell region, compared with the short-lived, allor-nothing river flows typical of the Gilbert and Flinders rivers (Ndehedehe et al., 2020).

Results from the current study confirm relationships between river flow and barramundi growth rates reported in other Australian regions (Robins et al., 2006). They also provide supporting evidence for a mechanism underlying the correlative relationships between peak wet season flows and subsequent increases in barramundi catch rates (Robins et al., 2005; Balston, 2009). There are multiple ways in which seasonal river flows can affect barramundi growth rates. Young-of-the-year barramundi exploit temporary aquatic habitats on the littoral estuarine margins, adjacent saltpans and upper reaches of tidal creeks that occur on the wide $(\sim 40 \mathrm{~km})$ flat coastal plains in the southern Gulf of Carpentaria (Russell \& Garrett, 1983). Temporary aquatic habitats are created (and replenished) by tidal inundation between October and March on seasonally large spring tides, but river flows extend their occurrence and accessibility, both spatially and temporally. These prey-rich habitats are speculated to support rapid growth, enhanced juvenile survival and thus enhanced recruitment (Russell \& Garrett, 1983). River flows deliver nutrients critical to maintaining estuarine primary productivity (Burford et al., 2020), which then supports higher order productivity including that of finfish, and also increase habitat access, including connectivity to upstream freshwater habitats (Davis, 1985; Blaber et al., 2008; Roberts et al., 2019). Increased juvenile growth rates may lead to increased catch rates in later years through improved survival of juveniles (Perez \& Munch, 2010), which can result in a stronger cohort (Campana, 1996) that is later encountered at higher numbers in the 
fishery (Ricker, 1979; Maunder et al., 2016). Freshwater flows are similarly important to a number of commercially targeted fishery species in northern Australia (Robins et al., 2005; Halliday et al., 2012), including the high-value banana prawn (Penaeus merguiensis, de Man, 1888) fishery (Duggan et al., 2019; Broadley et al., 2020) and mud crab (Scylla spp.) fishery (Meynecke et al., 2012b).

Biochronological approaches such as the current study can be powerful tools to retrospectively infer causative relationships between fish somatic growth rates and environmental conditions, but can also have important caveats and should be interpreted with this in mind. In particular, samples used in the current study are drawn from a historic otolith collection that is inherently vulnerable to "survivorship bias" (Delgado-Rodríguez \& Llorca, 2004). Barramundi harvested in the commercial set gill-net fishery in the Gulf of Carpentaria may have experienced a wide range of habitat uses as well as flow regimes. Barramundi are facultatively catadromous, thus juveniles that experience high river flows in their first wet season may migrate to freshwater habitats that are intermittently connected to the main river and estuary. These fish may become trapped for multiple years if subsequent wet seasons are poor or insufficient to reconnect such habitats and allow downstream movement. In poor wet seasons, previously rich freshwater nursery habitats can become resource-depleted (Warfe et al., 2011), and at the extreme, lethal - i.e. hot and anoxic, or drying out completely. Individuals with this life history trajectory would not appear in the estuarine fishery, and would be unavailable to the current study. In such instances, the multi-year sequence of river discharge volumes may be more influential than river discharge volume in any particular hydrological year.

Tag-recapture data for the southern Gulf of Carpentaria indicates that $>90 \%$ of barramundi remain within the catchment in which they were tagged (Sawynok, 2014). However, wet season flows in the southern Gulf of Carpentaria often result in extensive inundation of the lower coastal floodplains, particularly in moderate to high-flow wet seasons. River flows are known to disperse through "breakout" channels (e.g. Smithburne and Nassau rivers, Fig. 1, Supplementary Material 1, and Whitehouse 1943), providing connectivity between adjacent river systems and facilitating barramundi movement between neighbouring catchments. As such, a small number of individuals used in the current study may have been influenced by flows from an adjacent catchment, but we suggest the impacts on model results are likely to be minor for individual regions.

Atmospheric indices as drivers of otolith increment width

The current study provides atmospheric index predictors of juvenile barramundi growth rates, which can be used to integrate this relationship into broader-scale resource modelling, as well as to make predictions regarding biological changes to these ecosystems under the effect of climate change. This is particularly valuable for integration of our results into regional Gulf of Carpentaria models that are driven by largescale atmospheric variables, as well as for cautious extension of these results into Gulf catchments for which in situ river gauge data or high-quality river discharge modelling are unavailable.

SOI was a strong predictor of barramundi growth rates in Gulf of Carpentaria catchments. A strong positive effect of SOI was present in all study regions, with more intense La Niña wet seasons (sustained positive values of SOI $>8$, Bureau of Meteorology, $2012 b$ ) resulting in higher growth rates of juvenile barramundi (Table 3, Fig. 4e, i, m). This is in line with the established effects of ENSO on the Gulf of Carpentaria, and northern Australia more widely (Holbrook et al., 2009). La Niña wet seasons are associated with higher-than-average rainfall across northern Australia (Bureau of Meteorology, 2012b), resulting in increased banana prawn catches in the Gulf of Carpentaria (Vance et al., 1985) and increased mud crab catches in the western Gulf of Carpentaria (Meynecke et al., 2012a). The La Niña ENSO phase is known to influence growth rates across many taxa in northern Australia, including adult mangrove jack [Lutjanus argentimaculatus (Forsskål, 1775)] (Ong et al., 2015), spangled emperor [Lethrinus nebulosus (Forsskål, 1775)], Porites spp. corals, and the cypresspine tree Callitris columellaris (F. Mueller, 1866) in Western Australia (Ong et al., 2016). The speculated mechanistic link between SOI and growth rates of estuarine/marine taxa is increased freshwater discharge contributing to the downstream movement of nutrients and inundation of wetland areas, thereby stimulating high levels of primary productivity on river floodplains (Davies et al., 2008). 
The effect of the Phase 4 MJO index on juvenile barramundi growth rates was typically positive, in line with previous studies (Balston, 2008). However, this effect was only significant in the Mitchell region, possibly as a result of the small range of MJO values during the period for which otolith increment data was available for the Gilbert region (Table 1, Fig. 4i), or potentially as a result of the underlying differences in flow regime between the perennial Mitchell and intermittent Gilbert and Flinders rivers. The MJO index quantifies pulses of convective activity operating on a period of days to weeks (Madden \& Julian, 1972). High positive MJO values indicate a probability of intense monsoonal downpours, which would likely have brief but large implications for river discharge and coastal floodplain inundation. The difference in the effects of MJO-induced monsoonal downpours in the perennial and intermittent rivers may be the result of differences in catchment wetting processes, or fundamental geomorphological differences between the river types. In particular, the lower Mitchell catchment contains extensive productive floodplain lagoons that respond quickly to wet season flows and persist well after the peak wet season period (Ndehedehe et al., 2021). Conversely, the Flinders catchment typically has deep river channels that require significant flow events to overtop riverbanks and inundate wetlands; floodwaters subsequently recede quickly and floodplain inundation extent declines rapidly (Ndehedehe et al., 2020).

Integrating biological responses (e.g. barramundi otolith increment width) with large-scale atmospheric and climate processes is key to forecasting the effects of climate change on ecological and human systems. Unfortunately, the Gulf of Carpentaria is a highly variable and unpredictable region on an interannual timeframe, and the uncertain effects of climate change will act on this highly variable baseline. Predicted effects of climate change on the ENSO process and SOI are complex, but recent studies indicate that SOI extremes (i.e. severe El Niño and severe La Niña events) and resulting large interannual variation in precipitation patterns and total rainfall are likely to become more common (Perry et al., 2017). For juvenile barramundi, this would result in highly variable interannual growth rates, with potential impacts on natural mortality rates and recruitment if multiple extreme dry years were to occur in succession. The important potential interactive effects of river discharge volumes in successive years merits further research to improve forecasting and inform more dynamic and adaptive water extraction plans.

Climate forecasting also indicates that the amplitude of the MJO is likely to increase (Bui \& Maloney, 2018). A higher amplitude MJO could result in greater intensity and variability of both pulses of low pressure (wet conditions) and periods of high pressure (dry conditions). The increased intensity of low pressure systems would be expected to increase rainfall, river discharge, and consequently juvenile barramundi growth rates in the Mitchell region. However, concurrent changes to wind circulation patterns due to climate change mean that MJO pulses will be less predictable and more extreme (Bui \& Maloney, 2018), with low pressure conditions potentially crossing the line from beneficial to destructive (i.e. cyclonic).

Water development scenario testing

Subsequent scenario testing of a range of hypothetical water development scenarios in the Mitchell region indicated that different approaches and targets for water extraction can minimise the impact of freshwater harvesting on juvenile barramundi growth rates. Model results estimated that hypothetical water development scenarios in the Mitchell region that reduce EOS discharge by $18 \%, 8 \%$, and $3 \%$ could result in juvenile barramundi that grow $12 \%, 7 \%$, and $1 \%$ less during each of their first three years of life than they would have under existing flow conditions, respectively (Table 2, Fig. 5). Size-selective survival is important to natural mortality rates of young fish (Perez \& Munch, 2010). As such, reduced growth rates may negatively impact cohort survival, with subsequent deleterious effects on year-class strength (Staunton-Smith et al., 2004; Halliday et al., 2011, 2012), biomass (Tanimoto et al., 2012), and catch rates (Robins et al., 2005; Balston, 2008, 2009; Tanimoto et al., 2012).

Scenario testing is an important component of the water planning process (McGregor et al., 2018), and the current study provides a quantitative means of assessing the relative impact of different water development scenarios on juvenile barramundi growth rates. The model parameters presented here can be extended to a wider range of water development scenarios for the Mitchell River, and to water development scenarios for the Gilbert and Flinders rivers if 
robust modified river discharge timeseries become available for those regions. We strongly recommend replicating the water development scenario testing component of the current study across the range of water extraction scenarios proposed for the Gilbert and Flinders regions, as these rivers are also of interest for water resource development in northern Australia (Holz et al., 2013; Burford et al., 2020).

Further scenario testing can also investigate the relative effect of different water development components (e.g. dam number, size, and placement; surface water harvest volume; pump start thresholds; minimum EOS provisions) on EOS discharge and subsequent juvenile barramundi growth rates in order to determine the ideal water development strategy that strikes the best balance between human consumption and environmental requirements. For example, among the three development scenarios explored in this study, the smallest impact on juvenile barramundi growth rates $(1 \%$ reduction, Fig. $5 \mathrm{c}$ ) was achieved from the "low extraction" scenario, which included construction of the Nullinga dam high in the Mitchell River catchment (Table 2). It is also important to note that although the current study has identified the "low extraction" Nullinga dam scenario as minimally impacting juvenile barramundi growth rates, we make no inference about the effects of different water development scenarios on barramundi natural mortality rates, spawning success, recruitment success, or other key life history parameters, or any effects on other ecological assets in the Mitchell River (Pollino et al., 2018).

\section{Recommendations}

The current study delivers a key step towards providing environmentally informed growth estimates for barramundi population models in the Gulf of Carpentaria, which has been called for in stock assessments (Campbell et al., 2017; Streipert et al., 2019). In addition, our results can contribute to the framework for ecological assessment of water development scenarios (McGregor et al., 2018), explicitly incorporating water harvesting effects on juvenile barramundi growth rates.

It is important to note that variables included in the current analyses do not capture the full range of environmental influences on juvenile barramundi growth rates. Water temperature in particular is a fundamental determinant of growth rates in fish, with potentially large effects on otolith growth (Gillanders et al., 2012). Water temperature variables were not included in current modelling due to insufficient data at an appropriate timescale, and the limited suitability of proxy datasets (Supplementary Material 3). The Gulf of Carpentaria is typical of vast, remote, and datasparse parts of the world, where the quality and accuracy of predictive models are constrained by the limited spatiotemporal extent and resolution of environmental monitoring datasets. In light of this data scarcity, we strongly recommend increased deployment of in situ water temperature monitoring stations across the region to better understand the range and influence of thermal conditions in these highly variable aquatic systems.

This work also highlights two important knowledge gaps that are crucial to properly integrate our results into water resource planning and fishery management decisions. First, tag-recapture data (Sawynok, 2014) and otolith microchemical evidence (J. Robins, unpublished data) indicate that adult barramundi can move between estuaries in the Gulf of Carpentaria, such that some individuals captured in these study regions may have spent their juvenile years in neighbouring catchments. We recommend otolith microchemical assessments be carried out in each study region to quantify the relative frequency of intercatchment movement and improve predictions of the effects of river-specific freshwater harvesting on barramundi. In addition, routine otolith microchemical assessments should continue after implementation of any water development plans as part of a comprehensive environmental impact monitoring program. Second, the current study has inferred the magnitude of the relationship between otolith increment and actual somatic growth in barramundi, not measured it directly. Directly relating environmental drivers to somatic growth in barramundi using tag-recapture methods (Robins et al., 2006) is not always possible, with post hoc analysis of otolith archives representing a cost effective and pragmatic alternative to direct measurements of fish growth over considerable lengths of time. We recommend further research in this space to explicitly link otolith increment widths and somatic growth in barramundi, in particular through tag-recapture and otolith marking of juveniles. The relationship between otolith increment 
width and somatic growth in barramundi cannot be adequately addressed using routine samples from the commercial catch, which are legally restricted to capturing adult fish, and are thus typically older than the age ranges necessary to resolve this central question. Parametrising the relationship between otolith and juvenile fish growth can inform predictions of water development scenario effects on barramundi biomass and fishery harvest rates. Ideally, work linking otolith increment widths and somatic growth should be undertaken in all catchments targeted for water extraction, prioritising particularly data-sparse regions (e.g. Gilbert), and should also continue after implementation of any water development plans as part of a comprehensive environmental impact monitoring program. Once empirically linked to somatic growth, barramundi growth estimates via otolith increment widths can provide a robust, quantitative metric that can be monitored pre and post water resource development to identify the least impactful development scenario and monitor its compliance and success through time.

Acknowledgements This project was jointly funded through the Queensland Department of Agriculture and Fisheries and the Australian Government's National Environmental Science Program. Particular thanks to Dr Claire Krause of Geoscience Australia's Digital Earth Australia program (www.ga.gov.au/ dea) for providing Water Observations from Space data for initial exploratory analyses. Digital Earth Australia makes public good data from the United States and European Commission readily available to Australian government and industry. Thanks to Dr Chris Ndehedehe for providing GRACE and SWS remotely sensed datasets for initial exploratory analyses in support of this work, and to two anonymous reviewers for their input on the manuscript.

Authors' contributions J. Robins conceived of the project, secured funding, collected data, and contributed to the manuscript. S. Leahy collected data, carried out analyses, and contributed to the manuscript.

Funding This project was jointly funded through the Queensland Department of Agriculture and Fisheries and the Australian Government's National Environmental Science Program.

Data availability The otolith increment dataset generated and analysed during the current study is available at https://doi.org/ $10.6084 / \mathrm{m} 9$. figshare.14751747. River flow data for the Mitchell region is available via the Northern Australia Water Resources Assessment river model (https://nawra-river.shinyapps.io/river/ ). River flow data for the Gilbert and Flinders region are not publicly available at this time. They can be made available upon request to Queensland Hydrology, Queensland Department of Environment and Science. SOI and MJO datasets are publicly available from the Australian Bureau of Meteorology (bom.gov.au/climate/current/soihtm1.shtml) and the United States National Weather Service (cpc.ncep.noaa.gov/products/precip/ CWlink/daily_mjo_index/pentad.html), respectively.

\section{Declarations}

Conflict of interest All authors declare that they have no conflict of interest.

Ethical approval The animal remains used in this study were donated, and the life and death of all animals were not altered due to the subsequent scientific use of the remains. Therefore under Queensland Government policy, no animal ethics committee approval was required to carry out this study (www. business.qld.gov.au/industries/farms-fishing-forestry/ agriculture/livestock/animal-welfare/animals-science/ activities/dead-animals).

Consent for publication All authors, their employer, and the funding agency consent for this material to be published.

\section{References}

Acreman, M. C., I. C. Overton, J. King, P. J. Wood, I. G. Cowx, M. J. Dunbar, E. Kendy \& W. J. Young, 2014. The changing role of ecohydrological science in guiding environmental flows. Hydrological Sciences Journal 59: 433-450.

Balston, J., 2008. Chapter 4. Climate impacts on Barramundi and Banana Prawn fisheries of Queensland tropical East Coast. In: Halliday, I. \& J. Robins (eds) Environmental flows for sub-tropical estuaries: understanding the freshwater needs of estuaries for sustainable fisheries production and assessing the impacts of water regulation; Final Report FRDC Project No 2001/022, Coastal Zone Project FH3/ AF.

Balston, J., 2009. Short-term climate variability and the commercial barramundi (Lates calcarifer) fishery of north-east Queensland, Australia. Marine and Freshwater Research 60: 912-923.

Blaber, SJM, DA Milton, JP Salini (2008) Chapter 11 The Biology of Barramundi (Lates calcarifer) in the Fly River System. In Bolton, B. (ed) Developments in Earth and Environmental Sciences. vol 9. Elsevier, 411-426.

Black, B. A., R. J. Allman, I. D. Schroeder \& M. J. Schirripa, 2011. Multidecadal otolith growth histories for red and gray snapper (Lutjanus spp.) in the northern Gulf of Mexico, USA. Fisheries Oceanography 20: 347-356.

Black, B. A., G. W. Boehlert \& M. M. Yoklavich, 2005. Using tree-ring crossdating techniques to validate annual growth increments in long-lived fishes. Canadian Journal of Fisheries and Aquatic Sciences 62: 2277-2284 
Booth, D. J., 2014. Do otolith increments allow correct inferences about age and growth of coral reef fishes? Coral Reefs 33: 255-258.

Broadley, A., B. Stewart-Koster, R. A. Kenyon, M. A. Burford \& C. J. Brown, 2020. Impact of water development on river flows and the catch of a commercial marine fishery. Ecosphere 11: e03194.

Bui, H. X. \& E. D. Maloney, 2018. Changes in Madden-Julian Oscillation Precipitation and Wind Variance Under Global Warming. Geophysical Research Letters 45: 7148-7155.

Bureau of Meteorology, 2012a. Carpentaria Coast Australian Water Resources Assessment 2012. Bureau of Meteorology, 38.

Bureau of Meteorology, 2012b. Record-breaking La Niña events - an analysis of the La Niña life cycle and the impacts and significance of the 2010-11 and 2011-12 La Niña events in Australia. Bureau of Meteorology.

Burford, M. A., S. J. Faggotter \& R. Kenyon, 2020. Contribution of three rivers to floodplain and coastal productivity in the Gulf of Carpentaria: Component 1 final report. Griffith University, Brisbane, Australia.

Campana, S. E., 1996. Year-class strength and growth rate in young Atlantic cod Gadus morhua. Marine Ecology Progress Series 135: 21-26

Campana, S. E. \& S. R. Thorrold, 2001. Otoliths, increments, and elements: keys to a comprehensive understanding of fish populatons? Canadian Journal of Fisheries and Aquatic Sciences 58: 30-38.

Campbell, A. B., J. Robins \& M. F. O’Neill, 2017. Assessment of the barramundi (Lates calcarifer) fishery in the Southern Gulf of Carpentaria, Queensland, Australia Project Report. State of Queensland, Department of Agriculture and Fisheries, Brisbane, Queensland.

Casselman, J. M., 1990. Growth and Relative Size of Calcified Structures of Fish. Transactions of the American Fisheries Society 119: 673-688

Chilton, D. E. \& R. J. Beamish, 1982. Age determination for fishes studied by the Groundfish Program at the Pacific Biological Station. Canadian Special Publication of Fisheries and Aquatic Sciences 60.

Cobon, D. H., R. Darbyshire, J. Crean, S. Kodur, M. Simpson \& C. Jarvis, 2020. Valuing Seasonal Climate Forecasts in the Northern Australia Beef Industry. Weather, Climate, and Society 12: 3-14.

Coulson, P. G., B. A. Black, I. C. Potter \& N. G. Hall, 2014. Sclerochronological studies reveal that patterns of otolith growth of adults of two co-occurring species of Platycephalidae are synchronised by water temperature variations. Marine Biology 161: 383-393.

Cowan, T., R. Stone, M. C. Wheeler \& M. Griffiths, 2020. Improving the seasonal prediction of Northern Australian rainfall onset to help with grazing management decisions. Climate Services 19.

Crook, D. A., D. J. Buckle, Q. Allsop, W. Baldwin, T. M. Saunders, P. M. Kyne, J. D. Woodhead, R. Maas, B. Roberts \& M. M. Douglas, 2016. Use of otolith chemistry and acoustic telemetry to elucidate migratory contingents in barramundi Lates calcarifer. Marine and Freshwater Research 68: 1554-1566

Davies, P. M., S. E. Bunn \& S. K. Hamilton, 2008. 2 - Primary Production in Tropical Streams and Rivers. In Dudgeon, D. (ed) Tropical Stream Ecology. Academic Press, London, 23-42.

Davis, T. L. O., 1985. Seasonal changes in gonad maturity, and abundance of larvae and early juveniles of barramundi, Lates calcarifer (Bloch), in Van Diemen Gulf and the Gulf of Carpentaria. Marine and Freshwater Research 36: 177-190.

Davis, T. L. O. \& G. P. Kirkwood, 1984. Age and growth studies on barramundi, Lates calcarifer, in northern Australia. Australian Journal of Marine and Freshwater Research 35: 673-690

de Lestang, P., Q. A. Allsop \& R. K. Griffin, 2001. Assessment of fish passage ways on fish migration Fishery report. vol 63. Northern Territory Department of Business, Industry and Resource Development, Darwin.

Delgado-Rodríguez, M. \& J. Llorca, 2004. Bias. Journal of Epidemiology and Community Health 58: 635-641

Dormann, C. F., J. Elith, S. Bacher, C. Buchmann, G. Carl, G. Carré, J. R. G. Marquéz, B. Gruber, B. Lafourcade, P. J. Leitão, T. Münkemüller, C. McClean, P. E. Osborne, B. Reineking, B. Schröder, A. K. Skidmore, D. Zurell \& S. Lautenbach, 2013. Collinearity: a review of methods to deal with it and a simulation study evaluating their performance. Ecography 36: 27-46.

Doubleday, Z. A., C. Izzo, J. A. Haddy, J. M. Lyle, Q. Ye \& B. M. Gillanders, 2015. Long-term patterns in estuarine fish growth across two climatically divergent regions. Oecologia 179: 1079-1090

Duggan, M., P. Bayliss \& M. A. Burford, 2019. Predicting the impacts of freshwater-flow alterations on prawn (Penaeus merguiensis) catches. Fisheries Research 215: 27-37

Dunstan, D. J., 1959. The barramundi Lates calcarifer (Bloch) in Queensland waters. CSIRO Division of Fisheries and Oceanography, Melbourne, 22.

Fisheries Queensland, 2010. Fisheries Long Term Monitoring Program Sampling Protocol - Barramundi (2008 onwards) section Department of Employment, Economic Development and Innovation. Brisbane, Australia

Fisheries Queensland, 2012. Fisheries Long Term Monitoring Program Sampling Protocol - Fish Ageing section : Barramundi Department of Employment, Economic Development and Innovation. Brisbane, Australia

Garrett, R. N., Reproduction in Queensland barramundi (Lates calcarifer). In: Copland, J. W. \& D. L. Grey (eds) Management of Wild and Cultured Sea Bass/Barramundi Proceedings of an International Workshop Held at Darwin, N T Australia, 24-30 September 1986, 1987. Australian Centre for International Agricultural Research: Canberra.

Gillanders, B. M., B. A. Black, M. G. Meekan \& M. A. Morrison, 2012. Climatic effects on the growth of a temperate reef fish from the Southern Hemisphere: a biochronological approach. Marine Biology 159: 1327-1333

Gillanders, B. M. \& M. J. Kingsford, 2002. Impact of changes in flow of freshwater on estuarine and open coastal habitats and the associated organisms. Oceanography and Marine Biology: An Annual Review 40: 233-309

Grey, D. \& C. W. Sadoff, 2007. Sink or Swim? Water security for growth and development. Water Policy 9.

Grey, D. L., 1987. An overview of Lates calcarifer in Australia and Asia. In Copland, J. W. \& D. L. Grey (eds) Management of Wild and Cultured Sea Bass/Barramundi (Lates 
calcarifer): proceedings of an international workship held at Darwin, NT, Australia, 24-30 September 1986. ACIAR Proceedings No. 20, Darwin, NT.

Hallett, T. B., T. Coulson, J. G. Pilkington, T. H. Clutton-Brock, J. M. Pemberton \& B. T. Grenfell, 2004. Why large-scale climate indices seem to predict ecological processes better than local weather. Nature 430: 71-75

Halliday, I., J. B. Robins, D. G. Mayer, J. Staunton-Smith \& M. J. Sellin, 2011. Freshwater flows affect the year-class strength of barramundi Lates calcarifer in the Fitzroy river estuary, Central Queensland. Proceedings of the Royal Society of Queensland.

Halliday, I. A., T. Saunders, M. J. Sellin, Q. Allsop, J. B. Robins, M. McLennan \& P. Kurnoth, 2012. Flow impacts on estuarine finfish fisheries of the Gulf of Carpentaria FRDC Project 2007/002 Final report. Queensland Department of Agriculture, Fisheries and Forestry, Brisbane, Australia.

Hendon, H. H., M. C. Wheeler \& C. Zhang, 2007. Seasonal Dependence of the MJO-ENSO Relationship. Journal of Climate 20: 531-543

Herdter, E. S., 2014. Growth Rates in Gulf of Mexico Red Snapper, Lutjanus campechanus, Before and After the Deepwater Horizon Blowout. University of South Florida.

Holbrook, N. J., J. Davidson, M. Feng, A. J. Hobday, J. M. Lough, S. McGregor \& J. S. Risbey, 2009. El Niño Southern Oscillation Marine Climate Change in Australia, Impacts and Adaptation Responses, 2009 Report Card. vol 05/09. CSIRO Climate Adaptation National Research Flagship, Cleveland, Queensland, Australia.

Holz, L., S. Kim, C. Petheram, G. Podger, J. Hughes, M. Kehoe, D. Aramini, S. Podger, J. Lerat, P. Poulton, J. Hornbuckle \& J. M. Perraud, 2013. River system modelling for the Flinders and Gilbert Agricultural Resource Assessment case study analysis A technical report to the Australian Government from the CSIRO Flinders and Gilbert Agricultural Resource Assessment, part of the North Queensland Irrigated Agriculture Strategy. CSIRO Water for a Healthy Country and Sustainable Agriculture flagships, Australia.

Hudson, D., O. Alves, H. H. Hendon, E.-P. Lim, G. Liu, J.-J. Luo, C. MacLachlan, A. G. Marshall, L. Shi, G. Wang, R. Wedd, G. Young, M. Zhao \& X. Zhou, 2017. ACCESS-S1 The new Bureau of Meteorology multi-week to seasonal prediction system. Journal of Southern Hemisphere Earth Systems Science 67: 132-159

Hughes, J., A. Yang, B. Wang, S. Marvanek, L. Carlin, L. Seo, C. Petheram \& J. Vaze, 2017. Calibration of river system and landscape models for the Fitzroy, Darwin and Mitchell catchments A technical report to the Australian Government from the CSIRO Northern Australia Water Resource Assessment, part of the National Water Infrastructure Development Fund: Water Resource Assessments. Australia.

ICES, 2014. Report of the Workshop on Growth-increment Chronologies in Marine Fish: climate-ecosystem interactions in the North Atlantic (WKGIC). International Council for the Exploration of the Sea, Hamburg, Germany, 20.

Katayama, S., 2018. A description of four types of otolith opaque zone. Fisheries Science 84: 735-745

Kendy, E., K. W. Flessa, K. J. Schlatter, C. A. de la Parra, O. M. Hinojosa Huerta, Y. K. Carrillo-Guerrero \& E. Guillen,
2017. Leveraging environmental flows to reform water management policy: Lessons learned from the 2014 Colorado River Delta pulse flow. Ecological Engineering 106: 683-694

Kennard, M. J., B. J. Pusey, J. D. Olden, S. J. Mackay, J. L. Stein \& N. Marsh, 2010. Classification of natural flow regimes in Australia to support environmental flow management. Freshwater Biology 55: 171-193

King, J. R. \& G. A. McFarlane, 2003. Marine fish life history strategies: applications to fishery management. Fisheries Management and Ecology 10: 249-264

Kingsford, R. T., K. F. Walker, R. E. Lester, W. J. Young, P. G. Fairweather, J. Sammut \& M. C. Geddes, 2011. A Ramsar wetland in crisis - the Coorong, Lower Lakes and Murray Mouth, Australia. Marine and Freshwater Research 62: 255-265

LeBreton, G. T. O. \& F. W. H. Beamish, 2000. Interannual growth variation in fish and tree rings. Canadian Journal of Fisheries and Aquatic Sciences 57: 2345-2356

Lisonbee, J. \& J. Ribbe, 2021. Seasonal climate influences on the timing of the Australian monsoon onset. Weather and Climate Dynamics 2021: 1-31.

Madden, R. A. \& P. R. Julian, 1972. Description of Global-Scale Circulation Cells in the Tropics with a 40-50 Day Period. Journal of the Atmospheric Sciences 29: 1109-1123

Mallen-Cooper, M. \& B. P. Zampatti, 2018. History, hydrology and hydraulics: Rethinking the ecological management of large rivers. Ecohydrology 11: e1965

Mallen-Cooper, M. \& B. P. Zampatti, 2020. Restoring the ecological integrity of a dryland river: Why low flows in the Barwon-Darling River must flow. Ecological Management \& Restoration 21: 218-228.

Maneewong, S., Induction of spawning of sea bass (Lates calcarifer) in Thailand. In: Copeland, J. W. \& D. L. Grey (eds), Darwin, NT, 1987. p 138-141.

Martino, J. C., A. J. Fowler, Z. A. Doubleday, G. L. Grammer \& B. M. Gillanders, 2019. Using otolith chronologies to understand long-term trends and extrinsic drivers of growth in fisheries. Ecosphere 10: e02553

Martins, T. G., D. Simpson, F. Lindgren \& H. Rue, 2012. Bayesian computing with INLA: new features Computational Statistics and Data Analysis.

Matta, E. M., B. A. Black \& T. K. Wilderbuer, 2010. Climatedriven synchrony in otolith growth-increment chronologies for three Bering Sea flatfish species. Marine Ecology Progress Series 413: 137-145

Maunder, M. N., P. R. Crone, A. E. Punt, J. L. Valero \& B. X. Semmens, 2016. Growth: Theory, estimation, and application in fishery stock assessment models. Fisheries Research 180: 1-3

McCulloch, M., M. Cappo, J. Aumend \& W. Müller, 2005. Tracing the life history of individual barramundi using laser ablation MC-ICP-MS Sr-isotopic and Sr/Ba ratios in otoliths. Marine and Freshwater Research 56: 637-644.

McDougall, A., 2004. Assessing the use of sectioned otoliths and other methods to determine the age of the centropomid fish, barramundi (Lates calcarifer) (Bloch), using knownage fish. Fisheries Research 67: 129-141.

McGregor, G. B., J. C. Marshall, J. S. Lobegeiger, D. Holloway, N. Menke \& J. Coysh, 2018. A Risk-Based 
Ecohydrological Approach to Assessing Environmental Flow Regimes. Environmental Management 61: 358-374

McPhaden, M. J., X. Zhang, H. H. Hendon \& M. C. Wheeler, 2006. Large scale dynamics and MJO forcing of ENSO variability. Geophysical Research Letters 33

Meynecke, J.-O., M. Grubert, J. M. Arthur, R. Boston \& S. Y. Lee, 2012a. The influence of the La Niña-El Niño cycle on giant mud crab (Scylla serrata) catches in Northern Australia. Estuarine, Coastal and Shelf Science 100: 93-101

Meynecke, J.-O., M. Grubert \& J. Gillson, 2012b. Giant mud crab (Scylla serrata) catches and climate drivers in Australia - a large scale comparison. Marine and Freshwater Research 63: 84-94

Milton, D., I. Halliday, M. Sellin, R. Marsh, J. Staunton-Smith \& J. Woodhead, 2008. The effect of habitat and environmental history on otolith chemistry of barramundi Lates calcarifer in estuarine populations of a regulated tropical river. Estuarine Coastal and Shelf Science 78

Milton, D. A. \& S. R. Chenery, 2005. Movement patterns of barramundi Lates calcarifer, inferred from $87 \mathrm{Sr} / 86 \mathrm{Sr}$ and $\mathrm{Sr} / \mathrm{Ca}$ ratios in otoliths, indicate non-participation in spawning. Marine Ecology Progress Series 301: 279-291.

Mitsch, W. J., B. Bernal \& M. E. Hernandez, 2015. Ecosystem services of wetlands. International Journal of Biodiversity Science, Ecosystem Services \& Management 11: 1-4.

Moore, R., 1979. Natural Sex Inversion in the Giant Perch (Lates calcarifer). Marine and Freshwater Research 30: 803-813.

Moore, R., 1982. Spawning and earlier life history of barramundi, Lates calcarifer (Bloch), in Papua New Guinea. Australian Jounal of Marine and Freshwater Research 33: 647-661

Morrongiello, J. R., R. E. Thresher \& D. C. Smith, 2012. Aquatic biochronologies and climate change. Nature Climate Change 2: 849 .

Morrongiello, J. R., C. T. Walsh, C. A. Gray, J. R. Stocks \& D. A. Crook, 2014. Environmental change drives long-term recruitment and growth variation in an estuarine fish. Global Change Biology 20: 1844-1860.

Ndehedehe, C. E., A. O. Onojeghuo, B. Stewart-Koster, S. E. Bunn \& V. G. Ferreira, 2021. Upstream flows drive the productivity of floodplain ecosystems in tropical Queensland. Ecological Indicators 125.

Ndehedehe, C. E., B. Stewart-Koster, M. A. Burford \& S. E. Bunn, 2020. Predicting hot spots of aquatic plant biomass in a large floodplain river catchment in the Australian wet-dry tropics. Ecological Indicators 117.

Nguyen, H. M., A. N. Rountrey, J. J. Meeuwig, P. G. Coulson, M. Feng, S. J. Newman, A. M. Waite, C. B. Wakefield \& M. G. Meekan, 2015. Growth of a deep-water, predatory fish is influenced by the productivity of a boundary current system. Scientific Reports 5: 9044.

Oliver, E. C. J. \& K. R. Thompson, 2012. A Reconstruction of Madden-Julian Oscillation Variability from 1905 to 2008. Journal of Climate 25: 1996-2019.

Ong, J., A. Rountrey, J. Meeuwig, S. Newman, J. Zinke \& M. Meekan, 2015. Contrasting environmental drivers of adult and juvenile growth in a marine fish: implications for the effects of climate change. Scientific Reports, 5, 10859. https://doi.org/10.1038/srep10859.
Ong, J. J. L., A. N. Rountrey, J. Zinke, J. J. Meeuwig, P. F. Grierson, A. J. O’Donnell, S. J. Newman, J. M. Lough, M. Trougan \& M. G. Meekan, 2016. Evidence for climatedriven synchrony of marine and terrestrial ecosystems in northwest Australia. Global Change Biology 22: 2776-2786.

Pannella, G., 1971. Fish Otoliths: Daily Growth Layers and Periodical Patterns. Science 173: 1124-1127.

Pender, P. J. \& R. K. Griffin, 1996. Habitat History of Barramundi Lates calcarifer in a North Australian River System Based on Barium and Strontium Levels in Scales. Transactions of the American Fisheries Society 125: 679-689.

Perez, K. O. \& S. B. Munch, 2010. Extreme selection on size in the early lives of fish. Evolution 64: 2450-2457.

Perry, S. J., S. McGregor, A. S. Gupta \& M. H. England, 2017. Future Changes to El Niño-Southern Oscillation Temperature and Precipitation Teleconnections. Geophysical Research Letters 44: 10,608-10,616.

Petheram, C., T. A. McMahon \& M. C. Peel, 2008. Flow characteristics of rivers in northern Australia: Implications for development. Journal of Hydrology 357: 93-111.

Petheram, C., J. Hughes, C. Stokes, I. Watson, S. Irvin, D. Musson, S. Philip, C. Turnadge, P. Poulton, L. Rogers, P. Wilson, L. Seo, C. Pollino, A. Ash, T. Webster, S. Yeates, C. Chilcott, C. Bruce, D. Stratford, A. Taylor, P. Davies \& A. Higgins, 2018a. Case studies for the Northern Australia Water Resource Assessment. A technical report to the Australian Government from the CSIRO Northern Australia Water Resource Assessment, part of the National Water Infrastructure Development Fund Water Resource Assessments. CSIRO, Canberra.

Petheram, C., I. Watson, C. Bruce \& C. Chilcott (eds), 2018 b. Water resource assessment for the Mitchell catchment. A report to the Australian Government from the CSIRO Northern Australia Water Resource Assessment, part of the National Water Infrastructure Development Fund: Water Resource Assessments. CSIRO, Australia.

Pettit, N. E., R. J. Naiman, D. e. M. Warfe, T. D. Jardine, M. M. Douglas, S. E. Bunn \& P. M. Davies, 2017. Productivity and Connectivity in Tropical Riverscapes of Northern Australia: Ecological Insights for Management. Ecosystems 20: 492-514.

Pollino, C., E. Barber, R. Buckworth, M. Cadiegues, G. Cook, R. Deng, B. Ebner, R. Kenyon, A. Liedloff, L. Merrin, C. Moeseneder, D. Morgan, D. Nielsen, J. O'Sullivan, R. Ponce Reyes, B. Robson, D. Stratford, B. Stewart-Koster \& M. Turschwell, 2018. Synthesis of knowledge to support the assessment of impacts of water resource development to ecological assets in northern Australia: asset analysis. A technical report to the Australian Government from the CSIRO Northern Australia Water Resource Assessment, part of the National Water Infrastructure Development Fund: Water Resource Assessments. CSIRO, Canberra.

Ricker, W. E., 1979. 11 - Growth Rates and Models. Fish Physiology 8: 677-743.

Roberts, B. H., J. R. Morrongiello, A. J. King, D. L. Morgan, T. M. Saunders, J. Woodhead \& D. A. Crook, 2019. Migration to freshwater increases growth rates in a facultatively catadromous tropical fish. Oecologia 191: 253-260. 
Robertson, S. G. \& A. K. Morison, 1999. A trial of artificial neural networks for automatically estimating the age of fish. Marine and Freshwater Research 50: 73-82

Robins, J. B., I. Halliday, J. Staunton-Smith, D. G. Mayer \& M. J. Sellin, 2005. Freshwater-flow requirements of estuarine fisheries in tropical Australia: a review of the state of knowledge and application of a suggested approach. Marine and Freshwater Research 56: 1-18

Robins, J., D. Mayer, J. Staunton Smith, I. Halliday, B. Sawynok \& M. Sellin, 2006. Variable growth rates of the tropical estuarine fish barramundi Lates calcarifer (Bloch) under different freshwater flow conditions. Journal of Fish Biology 69: 379-391.

Rountrey, A. N., P. G. Coulson, J. J. Meeuwig \& M. Meekan, 2014. Water temperature and fish growth: otoliths predict growth patterns of a marine fish in a changing climate. Global Change Biology 20: 2450-2458

Rue, H., S. Martino \& N. Chopin, 2009. Approximate Bayesian inference for latent Gaussian models using integrated nested Laplace approximations (with discussion). Journal of the Royal Statistical Society, Series B 71: 319-392.

Russell, D. J., 2014. Lates calcarifer wild stocks: Their biology, ecology and fishery. In Jerry, D. R. (ed) Biology and Culture of Asian Seabass Lates calcarifer. CRC Press, Taylor and Francis Group, 77-101.

Russell, D. J. \& R. N. Garrett, 1983. Use by juvenile barramundi, Lates calcarifer (Bloch), and other fishes of temporary supralittoral habitats in a tropical estuary in Northern Australia. Australian Journal of Marine and Freshwater Research 34: 805-811.

Sawynok, B., 2014. Tagging in Gulf of Carpentaria Gilbert River to Flinders River 1985-2014. Infofish Australia, 11.

Smoliński, S., J. Morrongiello, P. van der Sleen, B. A. Black \& S. E. Campana, 2020. Potential sources of bias in the climate sensitivities of fish otolith biochronologies. Canadian Journal of Fisheries and Aquatic Sciences 77: 1552-1563.

Sponaugle, S., 2009. Daily Otolith Increments in the Early Stages of Tropical Fish. In Green, B. S., B. D. Mapstone, G. Carlos \& G. A. Begg (eds) Tropical Fish Otoliths: Information for Assessment, Management and Ecology. Springer Netherlands, Dordrecht, 93-132.

Staunton-Smith, J., J. B. Robins, D. G. Mayer, M. J. Sellin \& I. A. Halliday, 2004. Does the quantity and timing of fresh water flowing into a dry tropical estuary affect year-class strength of barramundi (Lates calcarifer)? Marine and Freshwater Research 55: 787-797

Stewart-Koster, B. \& S. E. Bunn, 2016. The ecology of water security. In Pahl-Wostl, C., A. Bhaduri \& J. Gupta (eds) Handbook on water security. Edward Elgar Publishing, Cheltenham.

Streipert, S., J. Filar, J. Robins \& O. Whybird, 2019. Stock assessment of the barramundi (Lates calcarifer) fishery in Queensland, Australia Technical Report. State of Queensland.

Stuart, I. G. \& S. C. McKillup, 2002. The use of sectioned otoliths to age barramundi (Lates calcarifer) (Bloch, 1790) [Centropomidae]. Hydrobiologia 479: 231-236.

Tanimoto, M., J. B. Robins, M. F. O'Neill, I. A. Halliday \& A. B. Campbell, 2012. Quantifying the effects of climate change and water abstraction on a population of barramundi (Lates calcarifer), a diadromous estuarine finfish. Marine and Freshwater Research 63: 715-726

Tonkin, Z., A. Kitchingman, J. Lyon, J. Kearns, G. Hackett, J. O’Mahony, P. D. Moloney, K. Krusic-Golub \& T. Bird, 2017. Flow magnitude and variability influence growth of two freshwater fish species in a large regulated floodplain river. Hydrobiologia 797: 289-301.

Vance DJ, DJ Staples, JD Kerr, (1985) Factors affecting year-toyear variation in the catch of banana prawns Penaeus merguiensis in the Gulf of Carpentaria, Australia. Journal du Conseil International pour l'Exploration de la Mar 42: 83-97.

Warfe, D. M., N. E. Pettit, P. M. Daviews, B. J. Pusey, S. K. Hamilton, M. J. Kennard, S. A. Townsend, P. Bayliss, D. P. Ward, M. M. Douglas, M. A. Burford, M. Finn, S. E. Bunn \& I. A. Halliday, 2011. The 'wet-dry' in the wetdry tropics drives river ecosystem structure and processes in northern Australia. Freshwater Biology 56: 2169-2195.

Warner, R. F., 1986. Hydrology. In Jeans, D. N. (ed) The Natural Environment Australia - A Geography. vol 1. Sydney University Press.

Wheeler, M. C. \& H. H. Hendon, 2004. An All-Season RealTime Multivariate MJO Index: Development of an Index for Monitoring and Prediction. Monthly Weather Review 132: 1917-1932.

Whitehouse, F. W., 1943. The natural drainage of some very flat monsoonal lands. Australian Geographer 4: 183-196

Winemiller, K. \& K. Rose, 1992. Patterns of Life-History Diversification in North American Fishes: implications for Population Regulation. Canadian Journal of Fisheries and Aquatic Sciences 49: 2196-2218.

Wright, C., B. B. Wedding, S. Grauf \& O. J. Whybird, 2021. Age estimation of barramundi (Lates calcarifer over multiple seasons from the southern Gulf of Carpentaria using FTNIR spectroscopy. Marine and Freshwater Research. https://doi.org/10.1071/MF20300

Xiao, Y., 2000. Use of the original von Bertalanffy growth model to describe the growth of barramundi, Lates calcarifer (Bloch). Fishery Bulletin 98: 835-841.

Xiao, Y. S., 1999. General age- and time-dependent growth models for animals. Fishery Bulletin 97: 690-701.

Yezerinac, S. M., S. C. Lougheed \& P. Handford, 1992. Measurement Error and Morphometric Studies: Statistical Power and Observer Experience. Systematic Biology 41: 471-482.

Zuur, A. F., E. N. Ieno, N. Walker, A. A. Saveliev \& G. M. Smith, 2009. Mixed Effects Models and Extensions in Ecology with R. Springer-Verlag, New York.

Zuur, A. F., J. M. Hilbe \& E. N. Ieno, 2013. A beginner's Guide to GLM and GLMM with R. Highland Statistics Ltd. , United Kingdom.

Publisher's Note Springer Nature remains neutral with regard to jurisdictional claims in published maps and institutional affiliations. 